\title{
cancers
}

ISSN 2072-6694

www.mdpi.com/journal/cancers

Review

\section{Oxidative and Nitrosative Stress in the Metastatic Microenvironment}

\author{
Ángel L. Ortega ${ }^{1}$, Salvador Mena ${ }^{2}$ and José M. Estrela ${ }^{1, *}$
}

1 Department of Physiology, Faculty of Medicine and Odontology, University of Valencia, 15 Av. Blasco Ibañez, 46010 Valencia, Spain; E-Mail: angel.ortega@uv.es

2 Green Molecular S.L., Pol. Ind. La Coma-Parc Cientific, 46190 Paterna, Valencia, Spain; E-Mail: salvador.mena@uv.es

* Author to whom correspondence should be addressed; E-Mail: jose.m.estrela@uv.es; Tel.: +34-963864649; Fax: +34-963864642.

Received: 8 February 2010; in revised form: 2 March 2010 / Accepted: 25 March 2010 / Published: 26 March 2010

\begin{abstract}
Metastases that are resistant to conventional therapies are the main cause of most cancer-related deaths in humans. Tumor cell heterogeneity, which associates with genomic and phenotypic instability, represents a major problem for cancer therapy. Additional factors, such as the attack of immune cells or organ-specific microenvironments, also influence metastatic cell behavior and the response to therapy. Interaction of cancer and endothelial cells in capillary beds, involving mechanical contact and transient adhesion, is a critical step in the initiation of metastasis. This interaction initiates a cascade of activation pathways that involves cytokines, growth factors, bioactive lipids and reactive oxygen and nitrogen species (ROS and RNS) produced by either the cancer cell or the endothelium. Vascular endothelium-derived $\mathrm{NO}$ and $\mathrm{H}_{2} \mathrm{O}_{2}$ are cytotoxic for the cancer cells, but also help to identify some critical molecular targets that appear essential for survival of invasive metastatic cell subsets. Surviving cancer cells that extravasate and start colonization of an organ or tissue can still be attacked by macrophages and be influenced by specific intraorgan microenvironment conditions. At all steps; from the primary tumor until colonization of a distant organ; metastatic cells undergo a dynamic process of constant adaptations that may lead to the survival of highly resistant malignant cell subsets. In this sequence of molecular events both ROS and RNS play key roles.
\end{abstract}


Keywords: metastases; tumor microenvironment; reactive oxygen species; reactive nitrogen species

\section{Introduction}

Cancer can be viewed as a complex cellular phenotype, which is associated with unlimited replicative potential, independence from growth signals with parallel resistance to growth-inhibitory signaling, evasion of cell death activation, sustained angiogenesis, as well as the ability of tissue invasion and metastasis [1]. Malignant tumors are invasive, and may metastasize to distant sites through the circulatory system. Consequently, metastatic spread, not the primary tumor burden, is the main cause of cancer-related deaths [2]. In fact control and treatment of metastases still represents a major, unsolved, scientific and clinical challenge.

Reactive oxygen species (ROS) are highly reactive molecules that are constantly produced in all aerobic organisms, mostly as a consequence of aerobic respiration. The term covers several types of chemical species, including free radicals such as superoxide $\left(\mathrm{O} 2^{-{ }^{-}}\right)$or hydroxyl $(\mathrm{OH} \cdot)$, and nonradicals such as hydrogen peroxide $\left(\mathrm{H}_{2} \mathrm{O}_{2}\right)$. Levels of ROS are reduced by antioxidant defenses, but increased by transition metals such as iron or copper and by exogenous agents such as ionizing radiation or ozone[3]. Similarly, nitrogen-derived free radicals are called reactive nitrogen species (RNS) and their utmost representative precursors are nitric oxide (NO) and peroxynitrite $\left(\mathrm{ONOO}^{-}\right)$[4]. $\mathrm{NO}$ is well known to be a product of the catalytic action of the nitric oxide synthase (NOS) enzyme family on L-arginine [5]. However, recent evidence suggests that it can also be formed by reduction of nitrite, which can arise in the body by ingestion or from bacterial metabolism [6]. Low levels of both ROS and RNS are continuously produced in mammalian cells and play important physiological roles [7]. These include processes as diverse as gene expression [8], cell proliferation and survival [9], pathogen clearance by the immune system, and blood vessel permeability. However, when the amount of ROS/RNS exceeds the capacity of the antioxidant machinery, the resulting oxidative/nitrosative stress may induce irreversible damages in all cellular macromolecules, including genomic DNA (Table 1). Therefore, maintenance of redox homeostasis is critical for cell function and survival, and its alteration is involved in the pathophysiology of many human diseases, such as cardiovascular diseases, diabetes, rheumatoid arthritis, neurological disorders (e.g., Alzheimer and Parkinson disease), or cancer[10-15].

The complex mechanisms involved in ROS and RNS actions make it difficult to treat the different events independently. This fact is particularly relevant when considering the influence of these reactive species in the pathophysiology and therapy of human cancers. Protein and DNA damage induced by ROS are linked to the failure to repair DNA damage, i.e., in K-ras mutation (12 G-T trasversions). For instance, these types of mutations are an early event in the development of adenocarcinoma of the lung and are present in $30 \%$ or more of all cases [16,17]. Besides recessive loss-of-function mutations in tumor suppressor genes such as p53 and p16, or dominant gain-of-function in oncogenes, chromosomal abnormalities, DNA adduct formation, methylation, and acetylation are characteristic of lung cancer and of other human tumors [18,19]. ROS and RNS have an active role in the induction of some of these alterations. In fact, levels of a hydroxyl-mediated DNA adduct, 8-hydroxydeoxyguanosine, 
are elevated in mice treated with NNK[4-(methylnitrosamino)-1-(3-pyridyl)-1-butanone], a tobaccospecific carcinogen[20]. Moreover, Jun oncogene stimulation by ROS and RNS has also been linked to lung cancer[21,22]. Oxidative modification of lipids induces products that react with DNA. Protein oxidation promotes mutagenesis through DNA polymerase alteration or inhibition of DNA repair enzymes [23,24].

Clinical and epidemiological research has provided strong evidence supporting the role of ROS and RNS in the etiology of cancer, due to different factors such as solar UV exposure[25,26], chemical carcinogens, lifestyle, diet and environment, or chronic inflammation conditions[27,28]; where high levels of free radicals are produced. Mutations in cancer-related genes, or post-translational modifications of proteins by nitration, nitrosation, phosphorylation, acetylation or poly ADPribosylation by free radicals or lipid peroxidation (Table 1) by products such as the reactive aldehydes malondialdehyde (MDA) and 4-hydroxy nonenal (HNE), are some key events that may increase cancer risk[29]. Indeed, free radicals can increase DNA mutation rates to levels comparable to those promoted by other well-known carcinogens (i.e., polycyclic aromatic hydrocarbons, or aflatoxins), and thus are considered powerful cancer initiators [30]. In vivo experiments with animal models also support a causal role for free radicals in cancer. Indeed knock-out mice for distinct antioxidant enzymes that regulate ROS levels in vivo (i.e., superoxide dismutase, SOD; and GSH peroxidase, GPx) not only have higher levels of ROS in their tissues, but also suffer from higher rates of spontaneous tumors[31]. Similarly, mice deficient in Mth1, a key enzyme involved in the repair of DNA oxidative lesions, also show higher rates of spontaneous lung, liver, and stomach tumors [32].

Table 1. Molecular damages induced by ROS and RNS.

\begin{tabular}{|c|c|}
\hline \multicolumn{2}{|l|}{ DNA } \\
\hline Point mutations & [33] \\
\hline DNA-DNA and DNA-protein crosslinks & {$[33]$} \\
\hline Sister chromatid exchanges & {$[33]$} \\
\hline Single- or double-strand breaks & {$[33]$} \\
\hline Increased 8-HO-dG levels with G-T transversions & {$[34]$} \\
\hline $\begin{array}{l}\text { Other oxidation-derived products such as 5-hydroxy-dC, 5-hydroxy-dU and uridine } \\
\text { glycol with C-T transitions }\end{array}$ & [33] \\
\hline \multicolumn{2}{|l|}{ Proteins } \\
\hline \multicolumn{2}{|l|}{ Amino acid oxidation } \\
\hline Post-translational modifications & {$[35]$} \\
\hline eNOS mediated Ras activation by $\mathrm{S}$-nitrosylation & [36] \\
\hline \multicolumn{2}{|l|}{ Lipids } \\
\hline Direct oxidation of polyunsaturated fatty acids present in lipids & [37] \\
\hline Indirectly by lipid synthesis inhibition, fatty acid desaturation, or lipase activation & [37] \\
\hline $\begin{array}{l}\text { Iron-mediated decomposition of lipid hydroperoxides can yield a plethora of follow-up } \\
\text { products such as conjugated dienes, hydrocarbon gases (e.g., ethane, ethene) and } \\
\text { carbonyl compounds such as malondialdehyde (MDA), alkenals, alkadienals, and } \alpha, \beta- \\
\text { unsaturated aldehydes (e.g., crotonaldehyde, acrolein). New studies on autoxidation of } \\
\text { arachidonic acid revealed that intermediate formation of monocyclic peroxides, } \\
\text { bicyclic endoperoxides, and dioxolane-isoprostane peroxides may also occur. }\end{array}$ & {$[36,38]$} \\
\hline
\end{tabular}


Furthermore, ROS have been shown to promote proliferation of various cancer cell types in vitro $[39,40]$, which highlights their cancer promoting potential. Exposure of several cancer cell lines to inflammation- or chemically-induced ROS boosts their migratory and invasive behaviors $[40,41,42]$, hence suggesting a role of free radicals in favoring the invasive phenotype. In fact, a growing body of evidence suggests that many cellular responses to oxidative and nitrosative stress are indeed regulated at the transcriptional level [43]. Nitrosylation or oxidation of critical Cys residues in the DNA-binding domains or at allosteric sites may regulate transcription of target (malignancyrelated) genes [43]. On the other hand, it is also known that exposure to free radicals above a certain threshold irreversibly leads to cell damage (Table 1), and eventually to cell death $[44,45]$. ROS and RNS also appear to be critical for the tumoricidal activity of the immune system $[27,46,47]$. Furthermore, several cancer chemotherapeutic agents (i.e., cisplatin or arsenic trioxide), as well as radiotherapy, are known to exert their cytotoxic effects through ROS-mediated mechanisms [44]. Therefore, the net result of pro- and anti-cancer ROS and RNS effects may likely determine the rate and extent of in vivo tumor progression. In this review, we will focus on the role of ROS and RNS in regulating cancer cell dynamics and survival in the metastatic microenvironment, where interaction with endothelial cells, extravasation, growth, and angiogenesis are critical steps in the process of metastatic invasion.

\section{Metastases}

\subsection{Biology and the Seed and Soil Hypothesis}

Tumor formation and metastasis classically includes DNA damage and mutagenesis, causing transformation of normal cells into preneoplastic cells (initiation), followed by selective clonal expansion (promotion), and a second mutagenic mechanism responsible for the ability of some malignant cells to acquire more aggressive characteristics (progression). Malignant tumors are invasive and may reach distant sites through the circulatory system [48]. The classical simplification of metastasis in local invasion, intravasation, survival in the blood and lymphatic system, extravasation, and colonization, has helped to understand and rationalize the complex set of factors and properties that must be acquired by a cancer cell in order for it to be considered malignant [49]. In practice, although cancer is a genetic disease, mutagenic transformations are not sufficient to acquire metastatic competence, in fact many oncogene-driven mouse models of cancer are not able to automatically establish metastases [50].

Although seeding can occur in multiple organs, in many cases metastatic tumors grow only in one or just in a few [51]. Steven Paget's "seed and soil" hypothesis introduced the concept that a receptive microenvironment is required for the development of metastasis [52]. Previously to Paget hypothesis, it was thought that tumor dissemination was determined by mechanical factors that caused tumor cell emboli in the vasculature[53]. However, now we know that the microenvironment clearly has important effects on tumor and metastasis development. There is evidence that cancer cells are able to remain in a dormancy state (a state of cellular quiescence in the G0 phase of the cell cycle) even for many years [49,54-56], or remain in a balanced state of proliferation and apoptosis [49,57]. The microenvironment may suppress the malignancy of potentially metastatic cells, but likewise their 
reactivation to form a new tumor or metastasis probably occurs through perturbations in the microenvironment [58].

\subsubsection{Tumor Microenvironment}

The complex and paradoxical role of ROS and RNS in tumorigenesis and metastasis have long been studied [59, 60]. Early studies associated inflammation and carcinogenesis. In 1863 Rudolf Virchow already noticed the presence of leukocytes in neoplastic tissues [61]. Since Virchow's observations, many different studies have supported that tumors can originate at the sites of chronic inflammation or infection [62]. Later studies have shown the relationship between NO and the immune response of macrophages [63], or how deletion or expression of inducible NOS (iNOS) can regulate development or growth of several types of cancer [64-66]. Altogether, these observations suggest that ROS and RNS have multiple physiological and pathological effects, depending on the tumor microenvironment, concentration, and spatial and temporal constraints.

\subsubsection{Tumorigenesis}

Environmental agents such as cigarette smoke, xenobiotics, lifestyle, diet, chronic ultraviolet B exposure, and sustained cellular injuries can generate ROS and RNS production, which can function as chemical effectors in tumorigenesis [25,26,37,67-69]. DNA damage (Table 1), leading to activation of oncogenes and/or non-expression of tumor suppressor proteins, is one of the plausible mechanisms by which ROS and RNS can promote carcinogenesis. Mutations in the oncogene RAS and tumor suppressor gene $P 53$ have been observed in many types of human cancers [70,71]. Transition-type mutations at dipyrimidine sites and $\mathrm{G}: \mathrm{C}$ to $\mathrm{T}: \mathrm{A}$ transversions, in addition of being induced by the presence of 8-oxoguanine during DNA replication [37], are observed in $R A S$ and P53 genes in human skin cancers of sun-exposed areas and in UV-induced mouse skin cancers [72]. Furthermore, ROS and RNS induce protein and cellular membranes damages (Table 1). Occasionally, oxidation and nitrosation may represent an advantage for tumor survival, proliferation stimulation and cell death inhibition [73]. In vivo studies have shown that knock-out mice for distinct antioxidants enzymes (i.e., SOD and GPx) not only having higher levels of ROS in their tissues, but also higher rates of spontaneous tumors [31].

The role of intracellular redox state in regulating growth, cell signaling, and/or gene expression is becoming recognized as an important issue. Indeed, alterations in receptor or cytoplasmic tyrosine kinases, levels of specific growth factors, intracellular processes for conveying membrane signals to the nucleus, or the regulation of DNA replication, have been shown in neoplastic cells [15].

\subsubsection{Invasion}

ROS- and RNS-induced post-translational modifications of proteins regulate a large variety of cellular functions and signaling events. Accumulating evidence shows that free radicals play an important role in cell invasion. In fact, exposure of several cancer cell lines to inflammation- or chemically-induced ROS boost their migratory and invasive behavior [40-42]. Epithelial mesenchymal transition (EMT) is not only a physiological mechanism for development and tissue remodeling, but 
also a pathological mechanism associated with various diseases including inflammation, fibrosis and cancer [74]. During EMT, cell-cell molecular adhesion is decreased, whereas cell-extracellular matrix adhesion is increased, which favors cell migration and invasion. ROS and NO play a pivotal role in the cell-cell dissociation process, since they can regulate the activity of Src kinase. Src is known to be activated in several cancers, and there is convincing evidence that increased Src activity is associated with a more invasive and aggressive phenotype [75]. A number of studies suggest that Src also plays an important role in the cellular response to ROS, because Src-specific inhibitors and dominantnegative Src mutants strongly attenuate cellular response to ROS [76-79]. Whether ROS activate or inactivate Src is controversial, since it participates in the regulation of numerous cellular processes such as cell survival, cytoskeleton reorganization, DNA synthesis, and cell division [80,81]. Different oxidation loci seem to plausibly explain Src activity: oxidation of $\mathrm{Cys}_{277}$ leads to the formation of a disulfide homodimer that inactivates Src activity [82], whereas mutations in $\mathrm{Cys}_{483}, \mathrm{Cys}_{487}, \mathrm{Cys}_{496}$, and Cys $_{498}$ abolish inactivation of the kinase by known inhibitors binding to cysteine residues such as the SH-alkylating agents BIMP and NAM or by mercury ions [83-85]. In addition, cysteine oxidation is important for regulation of the Src kinase after integrin-mediated cell adhesion [86]. Furthermore, ROS induce cell-cell dissociation by endocytosis of N-cadherin mediated by Src kinase phosphorylation and internalization of p120-catenin, which implies loss of epithelial integrity and transient Rho/Rho kinase pathway activation (as it occurs in the initial phase of EMT). The $\mathrm{H}_{2} \mathrm{O}_{2}$-induced Src activation also induces activation of NF- $\mathrm{BB}$ leading to $M n S O D$ expression, which reduces oxidative stress. This indicates that oxidative stress-induced cell-cell dissociation might be required for the initial step of EMT, but is not sufficient for stable induction of EMT [87].

NOS activity has been associated with tumor growth and tumor grade. Nitrosylation of RAS has been related to initiation and maintenance of tumors [36]. Moreover, NO may activate c-Src through cysteine modification [88]. NO causes S-nitrosylation of c-Src at $\mathrm{Cys}_{498}$ to stimulate its kinase activity resulting in tumor promotion and invasion [89]. For instance, c-Src activation by $\beta$-estradiol, observed in breast cancer MCF7 cells, depended on production of NO. Furthermore, this NO-mediated Src activation was critical for reducing the levels of E-cadherin and disrupting cell-cell contacts after $\beta$-estradiol stimulation [89]. Loss of E-cadherin activates diverse pathways inducing cell invasion[90].

\section{Interaction between Metastatic and Endothelial Cells}

\subsection{Adhesion, Death, and Survival}

Tumor metastasis is attributed not only to the abnormalities of cancer cells, but also to changes induced by the interaction of cancer cells with the surrounding cells/tissues. Indeed, metastases formation involves interactions between tumor cells and a changing microenvironment, which influences cell proliferation, migration, invasion, colonization, and survival [91,92].

Cancer cells that survive the circulatory system and reach different organs/tissues interact with the vascular endothelium before extravasation to begin secondary colonization (Figure 1). Two mechanisms have been proposed to explain this process [93]. Using fluorescence-tagged tumor cells and video-capturing image techniques, Weiss et al. found that many tumor cells injected intraperitoneally into mice were arrested in capillaries [94]. Tumor cells often aggregate with platelets, 
and due to their mass they were observed physically trapped in the capillaries (Figure 1). Arrested tumor cells could remain apparently inactive (senescent?), start growing and extravasate by secreting proteolytic enzymes and rupturing the blood vessel [95], or die due to deformation and surfacemembrane rupture [94]. NO was found to inhibit the aggregation of platelets via a cGMP-dependent mechanism [96]. In fact, although the ability of metastatic cells to form aggregates with platelets correlates with their metastatic potential, it is inversely proportional to NO generation [97].

Figure 1. Invasion of the liver by metastatic melanoma cells. Circulating cancer cells attached to the endothelium of pre-capillary arterioles or capillaries may follow two mechanisms of extravasation: (a) intravascular proliferation, formation of a tumor thrombus, and eventual vessel rupture and microinflammation; (b) rolling and migration through vessel fenestrae. Invading cancer cells will then form micrometastases within the normal lobular hepatic architecture, in a mechanism regulated by cross-talk with the stroma. Angiogenesis activation will facilitate metastases grow and spread. High ROS and RNS levels released by the vascular endothelium cause tumor cytoxicity before extravasation, however once organ colonization starts, lower ROS and RNS levels may favor metastatic growth.
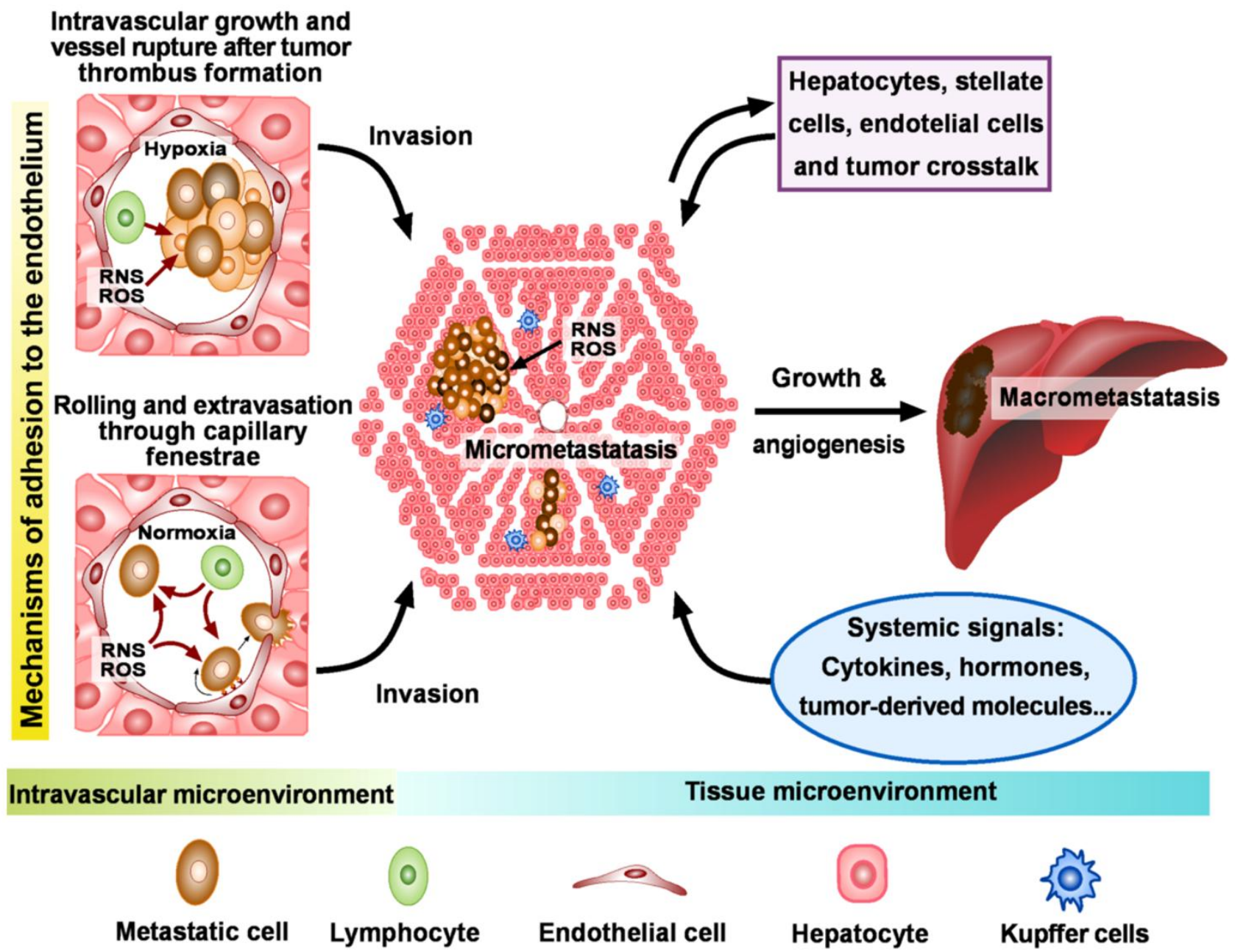
Alternatively the mechanism of metastatic cell extravasation may mimic the infiltration of leukocytes to the inflammatory site, in a process requiring adhesion of tumor and endothelial cells (Figure 1). Because many cancer cells express adhesion molecules, which are also expressed on the migrating leukocytes [98], it is generally accepted that metastatic cells use a similar strategy for adhesion to the endothelial cells during metastatic pre-invasion. In this sense, chemokines are important constituents of the tumor microenvironment at metastatic sites, dictating directionality of chemokine receptor-expressing tumor cells, facilitating their adhesion and extravasation, and eventually contributing to organ selectivity [99]. Therefore, although mechanical trapping at the capillaries is indeed observed, the biochemical organ microenvironment presumably plays a critical role in attracting circulating tumor cells to specific microcirculatory areas [100].

Adhesion of metastatic cells to the vascular endothelium is a mechanism mediated by several factors, such as cell adhesion molecules (integrins, selectins, cadherins), immunoglobulins, and cytokines [101-103].

Initial contact between metastatic cells and the endothelium ("docking") is weak and transient, and likely mediated by carbohydrate-carbohydrate recognition [104]. For instance, interaction between murine B16 melanoma (B16M; widely used as an experimental model to study the metastatic process) and the hepatic sinusoidal endothelium (HSE) involves mannose receptor-mediated melanoma cell attachment to the HSE, which subsequently causes proinflammatory cytokine release (TNF- $\alpha$, IL-1 $\beta$, and IL-18), and the VCAM-1-dependent adherence (reinforcing or "locking" the initial intercellular binding) [105]. Murine B16M variant cell lines with low (B16-F1) or high (B16-F10) survival and growth potential in vivo are frequently used in experimental metastases research. The B16M is a rapidly growing anaplasic tumor that produces melanin and grows indefinitely in vitro under appropriate conditions [106]. After inoculation of this tumor into syngenic mice, it can easily colonize different organs. Some metastatic B16M cells expressed high levels of the integrin VLA-4, the ligand for VCAM-1 on activated endothelial cells [107,108]. Endothelial cells, upon exposure to cytokines released during interaction with metastatic cells, undergo profound alterations of their function that involve gene expression changes, de novo protein synthesis, and production of ROS and RNS [104]. In the B16M model, HSE releases large amounts of ROS in response to endotoxins and IL-1. Such proinflammatory mediators promote cancer cell adhesion, invasion and proliferation. In fact, VCAM-1 gene expression in HSE is coupled to an oxidative stress-dependent mechanism [109,110]. Rolling and early adhesion of B16M cells to the HSE, IL-1-dependent endothelial release of $\mathrm{H}_{2} \mathrm{O}_{2}$ through IL-18, and late adhesion of surviving melanoma cells are sequential steps during B16M cell attachment to the HSE that occur in a short period (3-6 h), and enhance melanoma cell adhesion. These mechanisms would likely compensate for ROS-induced direct cytotoxic effects on adherent, vulnerable melanoma cells, leading to the metastatic progression of $\mathrm{H}_{2} \mathrm{O}_{2}$-resistant melanoma cells [111,112]. Low micromolar levels of ROS, which act as intra- and/or intercellular messengers promoting growth and angiogenesis [113-115], would then benefit these $\mathrm{H}_{2} \mathrm{O}_{2}$-resistant metastatic cells during their secondary colonization [116]. In agreement with these facts, ROS scavengers have been proposed to be therapeutically effective in suppressing metastasis once secondary growth starts after extravasation [117].

Nevertheless, at this point, it is important to remark that immune cells are also present in the metastatic microenvironment. Both innate and adaptive immunity participates in anti-tumor effects, including the activity of natural killer (NK) cells, natural killer T cells, macrophages, neutrophils and 
eosinophils, complement, various cytokines, specific antibodies, and specific T cytotoxic cells. Upon activation, neutrophils and macrophages are able to kill tumor cells, but they can also release ROS, angiogenic and immunosuppressive substances [27]. Indeed, inflammatory cells and immunomodulatory mediators present in the tumor microenvironment polarize the host immune response toward specific phenotypes impacting tumor progression [118].

Moreover, exposure of metastatic cells to ROS levels, which may be somehow in the middle between high (necrotic) and low (signaling) concentrations, could also induce cellular senescence and apoptosis and therefore function as anti-tumorigenic species[15]. This can certainly occur in the metastatic microenvironment where gradients of ROS are expected.

On the other hand, NO signaling has been also involved in regulating tumor proliferation, apoptosis, adhesion, migration, invasion, and angiogenesis [119,120]. Indeed, in many different types of cancer, expression of NO synthases, mainly the iNOS isoform, has been positively correlated with tumor invasion and angiogenesis [121-123]. However, NO may regulate cancer cell adhesion to the vascular endothelium either positively or negatively (e.g., [124]), a fact likely due to the variability in the NO concentration in tissues, either within cells or at the extracellular compartments. NO has been shown to inhibit adhesion to extracellular matrix components of many cells, including, eosinophils [125] and neutrophils [126]; whereas N-nitro-L-arginine (a general NOS inhibitor) or aminoguanidine (a specific iNOS inhibitor) increased neutrophil adhesion to endothelium [127]. In addition, NO was also shown to inhibit expression of cell adhesion molecules (e.g., ICAM-1) [128]. However, NO may have proadhesive effects as shown, for example, in rat brain microvascular endothelial cells, where expression of ICAM-1 was upregulated synergistically by VEGF and NO [129]. This process was mediated through a phosphatidylinositol-3-OH-kinase (PI3K)/AKT pathway: VEGF caused phosphorylation of AKT by PI3K, leading to production of NO [129].

In addition, a natural defense mechanism against cancer metastasis has been detected, whereby the arrest of tumor cells in the liver induces endogenous NO release, leading to sinusoidal tumor cell killing and reduced hepatic metastasis formation [130]. Based on this evidence, generation of NO concentrations in the high micromolar range, by NO donor drugs or gene therapy with iNOS, has been shown to inhibit tumor growth [120,131]. Nevertheless, the role of iNOS during tumor development is highly complex and is still not completely understood. Both promoting and deterring actions have been described, presumably depending upon the local concentration of iNOS within the tumor microenvironment. In particular, pivotal effects such as malignant transformation, angiogenesis, and metastasis are modulated by iNOS. On the other hand, NO derived from macrophages has a potentially cytotoxic/cytostatic effect on tumor cells [132].

Within the tumor microenvironment, NO can be produced by several cells (tumor cells, macrophages, endothelial or stromal cells). Isolated HSE cells treated in vitro with TNF- $\alpha$ and IFN- $\gamma$, a manoeuvre that mimics the proinflammatory scenario of the metastatic microenvironment, release NO and $\mathrm{H}_{2} \mathrm{O}_{2}$ in the culture medium [133]. Co-culture of these endothelial cells with B16M cells showed that, during the adhesion process, most of the $\mathrm{NO}$ and $\mathrm{H}_{2} \mathrm{O}_{2}$ were generated by the HSE [133]. Moreover, endothelial $\mathrm{NO}$ and $\mathrm{H}_{2} \mathrm{O}_{2}$ caused a high percentage of tumor cell death in a concentrationdependent manner [133]. Interestingly, inhibition of NO production using HSE cells isolated from eNOS-deficient $\left(\mathrm{eNOS}^{-/}\right.$) mice (which abolished eNOS-dependent NO production) or L-NAME (an inhibitor of all NOS activities) showed that $\mathrm{H}_{2} \mathrm{O}_{2}$ released by the $\mathrm{HSE}$ did not induce tumor 
cytotoxicity [133]. However, $\mathrm{NO}$ was particularly tumoricidal in the presence of $\mathrm{H}_{2} \mathrm{O}_{2}$ because addition of exogenous catalase, which eliminates $\mathrm{H}_{2} \mathrm{O}_{2}$ released to the extracellular medium, decreased significantly tumor cytotoxicity [133]. These findings are in agreement with later reports showing inhibition of B16M lung metastasis by local release of eNOS-derived NO [134]. When we explored the chemical mechanisms by which $\mathrm{NO}$ and $\mathrm{H}_{2} \mathrm{O}_{2}$ are cytotoxic, we found that a major part of the effect requires the presence of trace metals capable of generating highly oxidant radicals, likely $\bullet \mathrm{OH}$ and-OONO $[133,135]$.

Therefore, it appears evident that the net production of $\mathrm{NO}$ and $\mathrm{H}_{2} \mathrm{O}_{2}$ released during the interaction between metastatic cells and the endothelium is critical to explain their pro- and anti-metastatic effects.

\subsection{Identification of Key Targets}

The liver is a major metastasis-susceptible site and represents an excellent organ for metastatic microenvironment-related studies. In the liver, as well as in other organs/tissues, some cancer cells resist and possibly deactivate anti-tumoral defense mechanisms, likely ignoring growth-inhibitory factors while responding to proliferation-stimulating factors released from tumor-activated hepatocytes, stellate and sinusoidal cells [104]. This leads initially to avascular micrometastasis generation in periportal areas of hepatic lobules. Hepatocytes and myofibroblasts derived from portal tracts and activated hepatic stellate cells are next recruited into some of these avascular micrometastases. These create a microenvironment that supports metastases development through the specific release of both proangiogenic factors and cancer cell invasion- and proliferation-stimulating factors [136].

As previously stated, ROS and RNS contribute to the elimination of circulating and capillaryarrested cancer cells [105,133]. Therefore, it appears plausible that antioxidant defenses may contribute to metastatic cell survival. In the B16M model, some preliminary observations support this possibility: B16M cells pretreated in vitro with the lipophilic antioxidant tocopherol (vitamin E) increased their survival in the hepatic sinusoids [137]; an increase in B16M cell glutathione ( $\gamma$-glutamyl-cysteine-glycine; GSH, the most prevalent non protein thiol in cells) content upon hydroxyurea treatment also transiently increased metastasis [138]; capillary survival decreased in GSH-depleted B16M cells [139]; whereas B16M cells with high GSH content showed higher metastatic activity in the liver than those with lower GSH content [140]. In parallel experiments it was observed that a high \% of B16M cells with high GSH content survived combined HSE-derived nitrosative and oxidative attack in vitro, and thus, these surviving cancer cells may likely represent the main task force in the metastatic invasion [133]. GSH appears directly involved in regulating metastatic cell survival in vivo, because GSH ester (which readily enters the cell and delivers free GSH [141]) pretreatment of B16M-F1 (a variant with low metastatic activity) increased their GSH by four-fold (reaching GSH values similar to those found in B16M-F10 cells) and the \% of arrested intact cells in the liver sinusoids after intrasplenic inoculation [142]. Interestingly, invasive B16M-F10 (iB16M) cells, isolated after in vitro interaction with the $\mathrm{HSE}$, showed a $\mathrm{NO} / \mathrm{H}_{2} \mathrm{O}_{2}$-dependent $\mathrm{GSH}$ depletion and a decrease in $\gamma$-glutamylcysteine synthetase ( $\gamma$-GCS) activity [142]. However, overexpression of $\gamma$-GCS heavy and light subunits led to a rapid recovery of cytosolic GSH [142]. Thus, since GSH content and metastatic growth appear to be directly related, maintenance of high intracellular levels of 
GSH may be critical for the extravascular growth of those metastatic cells that survive after interaction with the endothelium.

$\mathrm{NO} / \mathrm{H}_{2} \mathrm{O}_{2}$ damage also induces a transient impairment of the mitochondrial system for GSH uptake in invasive cells, and in addition, a decreased activity of respiratory complexes II, III, and IV, less $\mathrm{O}_{2}$ consumption and ATP levels, higher $\mathrm{NO}$ and $\mathrm{H}_{2} \mathrm{O}_{2}$ production, and lower mitochondrial membrane potential [142]. This is important, because mitochondria do not synthesize GSH [143] and mitochondrial GSH (mtGSH) depletion facilitates permeability transition pore complex (PTPC) opening, and the release of apoptosis-inducing molecular signals [144]. In fact, by using in vitro diethylmaleate or monochlorobimane (as thiol-depleting agents), we observed that B16M-F10 cells with low mtGSH levels were highly susceptible to TNF- $\alpha$-induced oxidative stress and death [142]. Therefore, specific depletion of the mtGSH pool may be a critical target to challenge survival of invasive cancer cells.

Furthermore, it was observed that different B16M cell line subsets, containing similar GSH levels, showed different rates of survival after in vivo interaction with the HSE [142]. Therefore, although GSH content status appears an important parameter for metastasis progression, other factors must also contribute to the survival of some cell subsets with high metastatic potential. Interestingly, the development of resistance to GSH depletion-induced cytotoxicity in CC531 colon carcinoma cells was shown to be associated with increased expression of the anti-apoptotic protein Bcl-2 [145]. Moreover, different reports indicated that increased Bcl-2 levels (in melanoma and other cancer cell types) associated with a concomitant increase in the intracellular GSH content (see e.g., [105]). Thus, a possible link between Bcl-2 and GSH in blocking metastatic cell death appeared plausible.

The Bcl-2 family members are characterized by the presence of one or several Bcl-2 homology domains and include pro-death and anti-death proteins [146]. Bcl-2 itself is an anti-death protein, and its over-expression has been linked to cancer development, metastatic growth, and chemotherapy resistance [147-151]. On the other hand, expression of pro-death genes, e.g., $B A X$ or $B A K$, is often reduced in cancer cells [152].

Regulation of Bcl-2 protein levels may include transcriptional and post-transcriptional control, protein translocation, and protein-protein interactions [153]. However, in cancer cells, whereas some reports show evidence for post-transcriptional down-regulation of $B C L-2$ (e.g., [154,155]), others demonstrate an overproduction of the Bcl-2 protein on the basis on increased $B C L-2$ mRNA levels (e.g. $[156,157])$. A possible explanation for this apparent paradox could be linked to the destabilizing potential of the $B C L-2$ mRNA adenine- and uracil-rich element, which can be regulated by different mechanisms [158]: half-life of the mRNA of $B C L-2$ in Jurkat cells is prolonged by protein kinase $C$ stimulation, but shortened by $\mathrm{C}(2)$-ceramide addition. This supports the view that $B C L-2 \mathrm{mRNA}$ stability plays a physiological role in modulating Bcl-2 levels.

The expression of apoptosis-related genes (e.g., BCL-2, P53, FAS, NO synthetases, etc.) may affect tumor growth and possibly metastatic inefficiency [149]. Takaoka et al. observed that bcl-2 overexpression in $\mathrm{B} 16 \mathrm{M}$ cells enhanced pulmonary metastasis [147]. In parallel, melanoma cells resistant to fas-mediated apoptosis were found to be more susceptible to metastasize [148]. Furthermore, although apoptotic $H$-ras and $v$-myc transformed metastatic fibroblasts labeled with green fluorescent protein were observed in the lungs, in vitro-induced $b c l$-2 overexpression in these cells conferred resistance to apoptosis $24-48 \mathrm{~h}$ after inoculation [150]. Thus, it is plausible that 
regulation of cell death mechanisms influences metastatic growth, at least in the early stages after attachment to the vascular endothelium.

Further investigations showed that $B C L-2$ was preferentially overexpressed in B16M-F10 cells as compared with the low metastatic F1 cell variant [142]. There was also a good correlation between increased gene expression and increased protein content, which, in these B16M cells, minimizes the effect of post-transcriptional regulation steps [142]. In vitro HSE-induced B16M-F10 cytotoxicity was almost 100\% when GSH-depleted metastatic cells (BSO-treated; buthionine sulfoximine, a specific GSH synthesis inhibitor) were treated with a Bcl-2 antisense oligodeoxynucleotide (bcl-2-AS) [142]. Furthermore, when BSO- and bcl-2-AS-pretreated B16M-F10 cells were inoculated intravascularly into mice, the number of intact arrested cells on the HSE decreased by $98 \%$ and the very small number of metastatic cell survivors (probably bearing molecular damages) [142] were not able to develop detectable colonies [142]. This suggests that intravascular granulocytes and/or the Kupffer cells, present in the metastatic microenvironment, probably eliminate those few survivors.

Recent reports show that, in addition to its anti-apoptotic properties, Bcl-2 can also inhibit multidrug resistance dependent-GSH efflux from metastatic cells [105,159], thus improving metastatic cell resistance against ROS, RNS, cytotoxic drugs and ionizing radiation. Consequently, based on in vitro and in vivo findings in B16M cells (on the interaction between endothelial and metastatic cells, and the effect of ROS and RNS), GSH and Bcl-2 appear candidates to challenge survival of cancer cells with high metastatic potential. Nevertheless, this approach must be validated for other tumor types, where other molecules may be additional critical targets.

\section{Invasion and Colonization}

\subsection{Angiogenesis and Metastatic Growth}

The development of new vessels from pre-existing ones is termed angiogenesis or neovascularization, and includes hemangiogenesis and lymphangiogenesis [160]. The induction of angiogenesis is a crucial early stage in the development and growth of most solid tumours, and is also necessary for haematogenous and/or lymphagenous dissemination of cancer cells [2,161].

Regarding metastases, after colonization, persistent growth of metastatic tumors requires the establishment of new vasculature to ensure nutrients and oxygen supply [58].

Despite studies in animal models indicating that tumor lymphangiogenesis was associated with metastasis, metastatic spread to lymph nodes in different models occurred in the absence of tumor lymphangiogenesis, presumably via pre-existing lymphatic vessels. This suggests that the importance of lymphangiogenesis in metastasis may vary, depending on parameters such as the tumor type, or the position of the primary tumor relative to the lymphatic network [162].

All blood vessels are lined with endothelial cells that must proliferate and migrate to tumoral cell targets [163]. Angiogenesis is also a complex multistep process of growth and remodeling involving degradation of the extracellular matrix, cell migration and proliferation, and tube formation [162].

Folkman showed that tumors cannot grow beyond 1-2 mm without new blood vessel formation [163], and suggested that dormant metastases fail to grow because of the lack of neoangiogenesis 
(“angiogenic dormancy”) [164]. Dormant metastases-associated senescent cells exhibited growth arrest (mainly in G1), likely due to the NO present in the microenvironment [8].

Angiogenesis is favored by a pro-angiogenic tumor microenvironment comprised of hypoxia, increased growth promoting factors/cytokines, decreased antiangiogenic factors, secretion of metalloproteinases (MMPs), and increased cycloxygenase-2 (COX-2) [163]

Although a vast variety of growth factors and cytokines act as inducers of angiogenesis, e.g., placental growth factor (PIGF), fibroblast growth factors (FGF-1 and -2), platelet-derived growth factor (PDGF), hepatocyte growth factor (HGF), angiopoietins (Ang-1 and -2), epidermal growth factor/transforming growth factor- $\alpha(\mathrm{EGF} / \mathrm{TGF}-\alpha)$ [162]; the vascular endothelial growth factor (VEGF), due to its selectivity for endothelial cells, is the most specific growth factor for the endothelium [163]. VEGF induction in different tissue led to massive cell infiltration, predominantly hematopoietic cells, to tumor perivascular sites [165]. VEGF-A is a potent angiogenic factor with some (weak) prolymphangiogenic effect, whereas VEGF-C and VEGF-D are potent lymphangiogenic factors [166].

New vessels are highly irregular, weak, and have incomplete endothelial linings and membrane basement. Thus, adhesion of cancer cells to a new endothelium increases resistance to blood flow, may decrease tumor perfusion, and cause tumor hypoxia [160]. Under hypoxic conditions, e.g., in the central area of the tumor mass where oxygen pressure is low, tumor cells adopt anaerobic bacteria-like characteristics, including low levels of mitochondrial oxidative phosphorylation [167]. Increased glycolysis and diminished mitochondrial activity are universal mechanisms common to all tumor cell types with low $\mathrm{O}_{2}$ availability and generically known as the "Warburg effect" [167,168].

Lack of oxygen and nutrients, extracellular acidity (induced by the release of $\mathrm{CO}_{2}$ and lactic acid), and the up-regulation of glycolysis are all metabolic conditions that favor angiogenesis, invasion, metastasis, and mutation in P53 [160].

Hypoxia in solid primary tumor tissues or the metastatic microenvironment, promotes stabilization and activation of hypoxia-inducible factor-1a (HIF-1a), which participates in activating erythropoiesis, glycolysis, angiogenesis, cell growth, metastasis, and p53, as well as in regulating transcription of ABC transporter genes and Bcl-2 [160]. Thus, establishing molecular links between hypoxia and tumor chemoresistance.

The proliferating tumor cells, their surrounding host stromal cells, and tumor-infiltrating inflammatory/immune cells create a tumor microenvironment that reflects a persistent inflammatory state [169]. This chronic inflammation is closely associated with angiogenesis [169].

During tumor growth or under circumstances of prolonged stress, such as chronic inflammation or hypoxia, cell heterotypic interaction plays an important role in driving tumor promotion. Among these cells are macrophages, neutrophils and lymphocytes [58, 170].

Inflammatory cells secrete a large number of cytokines and chemokines. Cytokines, such as interleukin-1 (IL-1) and tumor necrosis factor (TNF), can act directly on endothelial cells favoring tumor cell adhesion. This effect is mediated, at least in part, through the synthesis and expression of specific endothelial cell surface binding proteins [171], and through production of autocrine growth factors by the tumor cells [172]. These proinflammatory cytokines activate ROS and RNS generation [172]. For example, TNF- $\alpha$ enhances the formation of ROS by neutrophils and other cells, while IL-1- $\beta$, TNF- $\alpha$ and IFN- $\gamma$ stimulate the expression of iNOS in inflammatory and endothelial cells [172]. 
The macrophages infiltrating the tumor have a crucial role in regulating its progression [58]. The fibroblasts produce cytokines and proteases that can promote endothelial cell proliferation and might activate dormant cells and trigger angiogenesis and metastasis [58,173]. Macrophages, platelets, fibroblasts and tumor cells themselves are major sources of angiogenic factors such as bFGF, VEGF, prostaglandins- 1 and -2, in addition to inflammatory cytokines, chemokines, and NO [172].

Excessive formation of $\mathrm{NO}$ in the cancer microenvironment or at inflammatory sites promotes enhanced vascular permeability, immune cell infiltration, and cytotoxicity [167]. In addition, NO reacts with $\mathrm{O}_{2}^{-}$, generating $\mathrm{ONOO}^{-}$, which, besides damaging macromolecules, plays roles stimulating production of prostaglandins and activating MMPs. Prostaglandins induce the expression of several pro-inflammatory cytokines, which further enhance the production of ROS and RNS [167].

Free radicals react with membrane phospholipids generating hydroperoxides, lipoperoxides, and toxic aldehydes such as MDA, which in turn induce further adhesion of granulocytes to the endothelium and activation of intracellular pathways that produce more free radicals [172]. This molecular cascade causes DNA damage, post-translational modification of key oncoproteins, suppression of DNA repair enzymes, promotion of cell proliferation, inhibition of apoptosis, angiogenesis and metastasis, and suppression of host antitumor defense [169].

Lipoperoxides, such as the 4-HNE, form adducts with DNA, e.g., at codon 249 of the P53 gene [169], and at high concentrations induce DNA oxidation and apoptosis, and upregulate COX-2 expression [172]. COX-2 is a main enzyme induced by prostaglandins in inflammatory cells such as monocytes and macrophages (in cytokine-stimulated macrophages, iNOS enhanced the activity of COX-2 via S-nitrosylation); and non-inflammatory cells such as fibroblasts and endothelial cells [172]. COX-2 also plays a role in cancer development through angiogenesis (increased expression of VEGF, promotion of vascular sprouting, migration and tube formation, induction of MMPs, and activation of EGFR) [169]; and through the activation of different oncogenes, including $S R C, R A S, H E R-2$ and WNT [172].

The peroxidation of cell membranes is regulated by lipoxygenases (LOXs) and the phospholipid hydroperoxide-glutathione peroxidase or glutathione:lipid-hydroperoxide oxidoreductase (PH-GPx). LOXs catalyze the specific dioxygenation of polyenoic fatty acids, forming reactive fatty acid hydroperoxides. PH-GPx reduces organic and inorganic hydroperoxides by utilizing GSH as a reducing agent. LOXs have been found in different cancer tissues, including melanoma, prostate, and epidermal cancers, and their expression also correlates with tumor cell metastatic activity [172].

\subsection{Dynamic Adaptations and the Road to Perdition}

Studies on the organ distribution of B16M cells showed that less than $1 \%$ of all circulating cancer cells survive and may promote metastases [174]. Indeed, the majority of cancer cells entering the microvascular bed of the liver [175] and other organs [94] are killed within the first hours due to blood flow-associated mechanical trauma [176], their inability to withstand deformation [175], locally released ROS/RNS [133], and their susceptibility to the lytic action of immunocompetent intrasinusoidal lymphocytes and macrophages [177]. Thus, cancer spread and invasion of secondary tissues/organs appears poorly effective, a fact biologically expressed as "metastatic inefficiency" [103,178,179], which implies that only highly resistant cell subsets begin metastatic invasion and start secondary 
growth. Whether these cells correspond, totally or partially, to the so-called cancer stem cells (CSCs) is an open question. The marked resistance of CSCs towards classical antitumor regimens is mediated by the combination of several critical features, including relative dormancy, efficient DNA repair, high expression of multidrug-resistance-type membrane transporters and protection by a hypoxic niche environment [180]. Therefore, it is possible that invasive metastatic cells may represent a (heterogeneous?) subset highly enriched in CSCs.

Affecting invasive cells, high $\mathrm{NO}$ and $\mathrm{H}_{2} \mathrm{O}_{2}$ levels are damaging and eventually may cause cell death [44,131]. Nevertheless ROS and RNS often function as a double-edged sword, causing cell death when in excess (i.e., during interaction of cancer and endothelial cells) or protecting cells against apoptotic or necrotic inducers when present at physiological levels (i.e., during secondary metastatic growth within an invaded tissue). Indeed, stress can induce genetic and epigenetic alterations leading to the expansion of new tumor cell populations [181].

On the molecular background of this mechanism, microarray-based gene expression analysis revealed changes in approximately 2000 transcripts in the response of e.g., HL60 cells to low $\mathrm{H}_{2} \mathrm{O}_{2}$ concentrations in particular, including $200 \mathrm{GSH}$-related genes [182]. Some of these overexpressed genes are key factors in carcinogenesis, such as NF- $\kappa \mathrm{B}$ activation or DNA methylation, genes for cytokine and chemokine ligands and receptors, the redox regulator thioredoxin interacting protein, the histone deacetylase sirtuin, heat-shock proteins (e.g., HSP40 and HSP70) and the AP-1 transcription factor components Fos and FosB [182]. Moreover, ROS affect HIF-1 and VEGF expression in cancer cells (e.g., [183]), and are involved in regulating angiogenesis and tumor growth [181, 184]. On the other hand, NO also acts on several signaling pathways directly activating transcription factors, such as NF- $\kappa \mathrm{B}$ or AP-1, and thereby influences gene expression [43]. Nevertheless, RNS, in some cases, indirectly modulates activity or stability of e.g., HIF-1 or NF- $\mathrm{BB}$, or modulates accessibility of promoters via increased DNA methylation or histone deacetylation [185].

In B16M-F10 cells interacting with endothelial cells, $\mathrm{H}_{2} \mathrm{O}_{2}$ - and $\mathrm{NO}$-induced adaptations include cell adhesion molecule expression in both endothelial and cancer cells (see above), activation of the early growth response-1 transcription factor gene, activation of cancer and endothelial cell MMPs, increase of antioxidant enzymes such as MnSOD and catalase, and induction of key invasive growthrelated molecules such as VEGF-A, HIF-1 and protein $8[159,186]$. Moreover, although high NO levels down-regulate the antiapoptotic protein Bcl-2 and induce cytotoxicity in e.g., B16M-F10 cells [187], low NO levels induce S-nitrosylation of Bcl-2, which inhibits its ubiquitination and subsequent proteosomal degradation in, for example, lung cancer cells. Facts, among others, implicating NO as a potential key regulator of cell death resistance [188,189].

Therefore, although many molecular factors are involved, ROS and RNS are among those favoring selection and growth of highly resistant metastatic cells, and thus paving the way to patient perdition. ROS and RNS generation is not constant and their levels are variable under in vivo conditions, thus this process of selection must be dynamic. This implies that changing conditions within the tissue microenvironment, systemic/intraorgan signals, immune cells attacks, or therapy-related cancer cell stress, may cause a constant change in the genomic/proteomic profile of metastatic growing survivors. Therefore, efforts focusing studies on the biology of these highly resistant cell subsets could be key to improving the efficacy of cancer therapy. 


\section{Therapeutic Implications}

The effective treatment of highly resistant tumor cells, frequently small metastatic subpopulations, is consequently a priority of anticancer therapy. This notion is important due to the different efficacy rates observed in patients with apparently the "same tumor" (type, stage) and receiving the same treatment. Therefore, to improve cancer treatment efficacy it appears also necessary to better work out (a) early diagnosis; (b) prediction of tumor evolution and response to treatment; (c) drug/radiation dosage and time course, and (d) toxicity-derived side effects. Gene expression and pathway signatures might help in these tasks. This includes the development of some RT-PCR and microarray based multigene tests, i.e., which in breast cancer include: MammaPrint, Oncotype DX, BLN Assay, Theros Breast Cancer Index SM, MapQuant DX, ARUP Breast Bioclassifier, Celera Metastatic Score, eXagen BCtm, Invasive Gene Signature, Wound Response Indicator and Mammostrat. Two of these (Oncotype DX and MammaPrint) have been already incorporated into several diagnostic protocols. Nevertheless, the high diversity of ROS- and RNS-induced effects, and the influence of the complex tumor microenvironment (including spatial and temporal constraints) [59, 67], makes it difficult to establish a possible oxidative-nitrosative signaling signature [190].

Low levels of NO have been associated with increased cGMP-mediated ERK phosphorylation, a response that favors a pro-growth and anti-apoptotic behavior. However, these prosurvival effects are lost at higher NO concentrations, which increase phosphorylation and acetylation of p53, while low levels stimulate proliferation [191,192] and promote invasion and metastasis [193-196].

The dual role of ROS and RNS in oncology- both anti-neoplastic and pro-neoplastic - clearly suggest that the type of tumor, its cellular redox state, as well as the final concentration and the duration of exposure to ROS and NO, may be determinant. Based on these facts, a number of therapies, drugs and approaches have been developed. On one hand, antioxidant and antinitrosative compounds may contribute to protect the organisms against cancer initiation. In this sense, for instance, a lot of natural compounds with antioxidant activity have potential applications, e.g., curcumin [197,198],

resveratrol [199-202], pterostilbene [203,204], epigallocatechin-3-gallate [205,206], or quercetin [207,208]. In addition, although toxic effects were found, the use of the NOS inhibitor Nnitro-L-arginine in a single dose reduced the tumor blood volume in patients [209].

On the other hand, oxidative and nitrosative stress can contribute to tumor removal. In fact, many chemotherapeutic agents, as well as ionizing radiation, increase ROS and RNS production up to cytotoxic levels [59,210,211]. Different NO donors have been also proposed [120,212]. However, natural compounds (as those mentioned above) may increase cancer sensitivity to e.g., chemotherapy or induce cancer demise [187,213-219].

Moreover, ionizing radiation has been shown to increase drug delivery and therapeutic efficacy through an NO (increase)-dependent transient tumor reoxygenation [120].

Hence, NO properties as vasodilator, inhibitor of cell respiration, radiosensitizer, modulator of tumor immunity, and angiogenesis stimulator can be utilized to improve the efficacy of conventional antitumoral treatments. Nevertheless, our partial understanding of how RNS and ROS act in the tumor microenvironment implies limitations in order to develop effective treatments. Further basic research, as well as new NO donors, NOS agonists, modulators of tumor antioxidant defenses, patient selection, and combined treatments, should help to improve the efficacy of cancer therapy. 


\section{Future Directions}

ROS and RNS contribute to maintaining the malignant phenotype. Thus, further research is necessary to improve our understanding of the complex mechanisms that regulate their roles in tumor biology. Cancer cells exposed to low levels of these reactive species, or capable of resisting ROS/RNS-mediated injury, undergo a clonal selection that favors their survival. In this mechanism, activated oncogenes and/or inactivated tumor suppressor genes may result in activation of multiple transcription factors. At advanced stages, uncontrolled tumor growth and the development of stress conditions, such as hypoxia, acidosis, inflammation, and free radical overproduction, may further alter the activity of these transcription factors. These events may cause aberrant expression of multiple metastasis-related proteins and confer survival and growth advantages to metastatic cells. However, it is essential to take into account that metastatic cells are surrounded by the tumor stroma or microenvironment, which includes resident non-cancerous cells (fibroblasts, glial cells, epithelial cells, adipocytes, inflammatory cells, immunocytes, and vascular cells), connective tissue, extracellular matrix, and extracellular molecules. At present, there is a limited understanding of the complex relationship between metastatic cells and the surrounding host cells. For years researchers have focused on the cancer cell itself, but it is now acknowledged that metastatic cells and their stroma coevolve during tumor progression. Nevertheless, how normal cells or newly recruited cells are altered during metastatic progression, and how they reciprocally influence metastatic growth are poorly understood. Therefore, our knowledge on these questions must improve to permit the development of therapeutic strategies targeted at both the microenvironment and the tumor. Moreover, it may be possible to develop strategies to prevent metastatic growth based on our understanding of how alterations in the microenvironment affect that growth. Available technologies will provide the tools for a better understanding of the tumor microenvironment and for the development of tissue- or cellspecific targeting agents. In this sense, isolation and characterization of both metastatic and stromal cells appears critical in order to learn how to make the tumor microenvironment hostile to the tumor.

It is in this scenario where a complex balance between pro- and anti-metastatic ROS and RNS (possibly involving other cancer-, endothelium-or immune cell-derived cytotoxic/signaling molecules) regulate the progression of metastatic cells. Thus, gene expression, cell signaling, and proteomic profiles may help to identify (a) key targets involved in metastatic cell escape mechanisms, and (b) RNS- and ROS-induced adaptive responses in selected pools of invasive cells, in particular those that resist aggressive anti-cancer treatments.

\section{References}

1. Hanahan, D.; Weinberg, R.A. The hallmarks of cancer. Cell 2000, 100, 57-70.

2. Steeg, P.S. Tumor metastasis: mechanistic insights and clinical challenges. Nat. Med. 2006, 12, 895-904.

3. Oberley, T.D. Oxidative damage and cancer. Am. J. Pathol. 2002, 160, 403-408.

4. Espey, M.G.; Miranda, K.M.; Thomas, D.D.; Xavier, S.; Citrin, D.; Vitek, M.P.; Wink, D.A. A chemical perspective on the interplay between NO, reactive oxygen species, and reactive nitrogen oxide species. Ann. N. Y. Acad. Sci. 2002, 962, 195-206. 
5. Li, H.; Poulos, T.L. Structure-function studies on nitric oxide synthases. J. Inorg. Biochem. 2005, 99, 293-305.

6. Lundberg, J.O.; Weitzberg, E. NO generation from nitrite and its role in vascular control. Arterioscler. Thromb. Vasc. Biol. 2005, 25, 915-922.

7. Gutteridge, J.M.; Halliwell, B. Free radicals and antioxidants in the year 2000. A historical look to the future. Ann. N. Y. Acad. Sci. 2000, 899, 136-147.

8. Allen, R.G.; Tresini, M. Oxidative stress and gene regulation. Free Radic. Biol. Med. 2000, 28, 463-499.

9. Kamata, H.; Hirata, H. Redox regulation of cellular signalling. Cell Signal 1999, 11, 1-14.

10. Cerutti, P.; Shah, G.; Peskin, A.; Amstad, P. Oxidant carcinogenesis and antioxidant defense. Ann. N. Y. Acad. Sci. 1992, 663, 158-166.

11. Dhalla, N.S.; Temsah, R.M.; Netticadan, T. Role of oxidative stress in cardiovascular diseases. J. Hypertens. 2000, 18, 655-673.

12. Sayre, L.M.; Smith, M.A.; Perry, G. Chemistry and biochemistry of oxidative stress in neurodegenerative disease. Curr. Med. Chem. 2001, 8, 721-738.

13. Jenner, P. Oxidative stress in Parkinson's disease. Ann. Neurol. 2003, 53 Suppl. 3, S26-36; discussion S36-28.

14. Dalle-Donne, I.; Rossi, R.; Colombo, R.; Giustarini, D.; Milzani, A. Biomarkers of oxidative damage in human disease. Clin. Chem. 2006, 52, 601-623.

15. Valko, M.; Leibfritz, D.; Moncol, J.; Cronin, M.T.; Mazur, M.; Telser, J. Free radicals and antioxidants in normal physiological functions and human disease. Int. J. Biochem. Cell Biol. 2007, 39, 44-84.

16. Lacal, J.C.; Srivastava, S.K.; Anderson, P.S.; Aaronson, S.A. Ras p21 proteins with high or low GTPase activity can efficiently transform NIH/3T3 cells. Cell 1986, 44, 609-617.

17. Westra, W.H.; Slebos, R.J.; Offerhaus, G.J.; Goodman, S.N.; Evers, S.G.; Kensler, T.W.; Askin, F.B.; Rodenhuis, S.; Hruban, R.H. K-ras oncogene activation in lung adenocarcinomas from former smokers. Evidence that K-ras mutations are an early and irreversible event in the development of adenocarcinoma of the lung. Cancer 1993, 72, 432-438.

18. Belinsky, S.A. Role of the cytosine DNA-methyltransferase and p16INK4a genes in the development of mouse lung tumors. Exp. Lung Res. 1998, 24, 463-479.

19. Bennett, W.P.; Colby, T.V.; Travis, W.D.; Borkowski, A.; Jones, R.T.; Lane, D.P.; Metcalf, R.A.; Samet, J.M.; Takeshima, Y.; Gu, J.R.; et al. p53 protein accumulates frequently in early bronchial neoplasia. Cancer Res. 1993, 53, 4817-4822.

20. Chung, F.L.; Xu, Y. Increased 8-oxodeoxyguanosine levels in lung DNA of A/J mice and F344 rats treated with the tobacco-specific nitrosamine 4-(methylnitrosamine)-1-(3-pyridyl)-1butanone. Carcinogenesis 1992, 13, 1269-1272.

21. Szabo, E.; Riffe, M.E.; Steinberg, S.M.; Birrer, M.J.; Linnoila, R.I. Altered cJUN expression: an early event in human lung carcinogenesis. Cancer Res. 1996, 56, 305-315.

22. Volm, M.; van Kaick, G.; Mattern, J. Analysis of c-fos, c-jun, c-erbB1, c-erbB2 and c-myc in primary lung carcinomas and their lymph node metastases. Clin. Exp. Metastasis 1994, 12, 329-334.

23. Marnett, L.J. Oxyradicals and DNA damage. Carcinogenesis 2000, 21, 361-370. 
24. Wiseman, H.; Halliwell, B. Damage to DNA by reactive oxygen and nitrogen species: role in inflammatory disease and progression to cancer. Biochem. J. 1996, 313(Pt 1), 17-29.

25. Ananthaswamy, H.N.; Price, J.E.; Goldberg, L.H.; Bales, E.S. Detection and identification of activated oncogenes in human skin cancers occurring on sun-exposed body sites. Cancer Res. 1988, 48, 3341-3346.

26. Sander, C.S.; Chang, H.; Hamm, F.; Elsner, P.; Thiele, J.J. Role of oxidative stress and the antioxidant network in cutaneous carcinogenesis. Int. J. Dermatol. 2004, 43, 326-335.

27. Jakobisiak, M.; Lasek, W.; Golab, J. Natural mechanisms protecting against cancer. Immunol. Lett. 2003, 90, 103-122.

28. Ohshima, H. Genetic and epigenetic damage induced by reactive nitrogen species: implications in carcinogenesis. Toxicol. Lett. 2003, 140-141, 99-104.

29. Hussain, S.P.; Hofseth, L.J.; Harris, C.C. Radical causes of cancer. Nat. Rev. Cancer 2003, 3, 276-285.

30. Toyokuni, S. Novel aspects of oxidative stress-associated carcinogenesis. Antioxid. Redox Signal 2006, 8, 1373-1377.

31. Halliwell, B. Oxidative stress and cancer: have we moved forward? Biochem. J. 2007, 401, 1-11.

32. Tsuzuki, T.; Egashira, A.; Igarashi, H.; Iwakuma, T.; Nakatsuru, Y.; Tominaga, Y.; Kawate, H.; Nakao, K.; Nakamura, K.; Ide, F.; Kura, S.; Nakabeppu, Y.; Katsuki, M.; Ishikawa, T.; Sekiguchi, M. Spontaneous tumorigenesis in mice defective in the MTH1 gene encoding 8-oxodGTPase. Proc. Natl. Acad. Sci. USA 2001, 98, 11456-11461.

33. De Bont, R.; van Larebeke, N. Endogenous DNA damage in humans: a review of quantitative data. Mutagenesis 2004, 19, 169-185.

34. Wang, D.; Kreutzer, D.A.; Essigmann, J.M. Mutagenicity and repair of oxidative DNA damage: insights from studies using defined lesions. Mutat. Res. 1998, 400, 99-115.

35. Stamler, J.S.; Singel, D.J.; Loscalzo, J. Biochemistry of nitric oxide and its redox-activated forms. Science 1992, 258, 1898-1902.

36. Lim, K.H.; Ancrile, B.B.; Kashatus, D.F.; Counter, C.M. Tumour maintenance is mediated by eNOS. Nature 2008, 452, 646-649.

37. Goetz, M.E.; Luch, A. Reactive species: a cell damaging rout assisting to chemical carcinogens. Cancer Lett. 2008, 266, 73-83.

38. Yin, H.; Porter, N.A. New insights regarding the autoxidation of polyunsaturated fatty acids. Antioxid. Redox Signal 2005, 7, 170-184.

39. Irani, K.; Xia, Y.; Zweier, J.L.; Sollott, S.J.; Der, C.J.; Fearon, E.R.; Sundaresan, M.; Finkel, T.; Goldschmidt-Clermont, P.J. Mitogenic signaling mediated by oxidants in Ras-transformed fibroblasts. Science 1997, 275, 1649-1652.

40. Polytarchou, C.; Hatziapostolou, M.; Papadimitriou, E. Hydrogen peroxide stimulates proliferation and migration of human prostate cancer cells through activation of activator protein1 and up-regulation of the heparin affin regulatory peptide gene. J. Biol. Chem. 2005, 280, 40428-40435.

41. Okada, H.; Mak, T.W. Pathways of apoptotic and non-apoptotic death in tumour cells. Nat. Rev. Cancer 2004, 4, 592-603. 
42. Payne, S.L.; Fogelgren, B.; Hess, A.R.; Seftor, E.A.; Wiley, E.L.; Fong, S.F.; Csiszar, K.; Hendrix, M.J.; Kirschmann, D.A. Lysyl oxidase regulates breast cancer cell migration and adhesion through a hydrogen peroxide-mediated mechanism. Cancer Res. 2005, 65, 11429-11436.

43. Marshall, H.E.; Merchant, K.; Stamler, J.S. Nitrosation and oxidation in the regulation of gene expression. FASEB J. 2000, 14, 1889-1900.

44. Pelicano, H.; Carney, D.; Huang, P. ROS stress in cancer cells and therapeutic implications. Drug Resist. Updat. 2004, 7, 97-110.

45. Trachootham, D.; Zhou, Y.; Zhang, H.; Demizu, Y.; Chen, Z.; Pelicano, H.; Chiao, P.J.; Achanta, G.; Arlinghaus, R.B.; Liu, J.; Huang, P. Selective killing of oncogenically transformed cells through a ROS-mediated mechanism by beta-phenylethyl isothiocyanate. Cancer Cell 2006, 10, 241-252.

46. Wink, D.A.; Vodovotz, Y.; Laval, J.; Laval, F.; Dewhirst, M.W.; Mitchell, J.B. The multifaceted roles of nitric oxide in cancer. Carcinogenesis 1998, 19, 711-721.

47. Oliva, M.R.; Iradi, A.; Garrido, F.; Ramos, M.; Oltra, A.M.; Muniz, P.; Saez, G.T. Oxidative stress induces the expression of the major histocompatibility complex in murine tumor cells. Free Radic. Res. 2001, 35, 119-128.

48. Estrela, J.M.; Carretero, J.; Ortega, A. Glutathione, sulfur amino acids and cancer. In Glutathione and Sulfur Amino Acids in Human Health and Disease; John Wiley \& Sons: New York, NY, USA, 2009.

49. Nguyen, D.X.; Bos, P.D.; Massague, J. Metastasis: from dissemination to organ-specific colonization. Nat. Rev. Cancer 2009, 9, 274-284.

50. Minna, J.D.; Kurie, J.M.; Jacks, T. A big step in the study of small cell lung cancer. Cancer Cell 2003, 4, 163-166.

51. Husemann, Y.; Geigl, J.B.; Schubert, F.; Musiani, P.; Meyer, M.; Burghart, E.; Forni, G.; Eils, R.; Fehm, T.; Riethmuller, G.; Klein, C.A. Systemic spread is an early step in breast cancer. Cancer Cell 2008, 13, 58-68.

52. Paget, S. The distribution of secondary growths in cancer of the breast. 1889. Cancer Metastasis Rev. 1989, 8, 98-101.

53. Psaila, B.; Lyden, D. The metastatic niche: adapting the foreign soil. Nat. Rev. Cancer 2009, 9 , 285-293.

54. Cameron, M.D.; Schmidt, E.E.; Kerkvliet, N.; Nadkarni, K.V.; Morris, V.L.; Groom, A.C.; Chambers, A.F.; MacDonald, I.C. Temporal progression of metastasis in lung: cell survival, dormancy, and location dependence of metastatic inefficiency. Cancer Res. 2000, 60, 2541-2546.

55. Goodison, S.; Kawai, K.; Hihara, J.; Jiang, P.; Yang, M.; Urquidi, V.; Hoffman, R.M.; Tarin, D. Prolonged dormancy and site-specific growth potential of cancer cells spontaneously disseminated from nonmetastatic breast tumors as revealed by labeling with green fluorescent protein. Clin. Cancer Res. 2003, 9, 3808-3814.

56. Brackstone, M.; Townson, J.L.; Chambers, A.F. Tumour dormancy in breast cancer: an update. Breast Cancer Res. 2007, 9, 208.

57. Aguirre-Ghiso, J.A. Models, mechanisms and clinical evidence for cancer dormancy. Nat. Rev. Cancer 2007, 7, 834-846. 
58. Joyce, J.A.; Pollard, J.W. Microenvironmental regulation of metastasis. Nat. Rev. Cancer 2009, 9 , 239-252.

59. Ridnour, L.A.; Thomas, D.D.; Switzer, C.; Flores-Santana, W.; Isenberg, J.S.; Ambs, S.; Roberts, D.D.; Wink, D.A. Molecular mechanisms for discrete nitric oxide levels in cancer. Nitric Oxide 2008, 19, 73-76.

60. Schumacker, P.T. Reactive oxygen species in cancer cells: live by the sword, die by the sword. Cancer Cell 2006, 10, 175-176.

61. Balkwill, F.; Mantovani, A. Inflammation and cancer: back to Virchow? Lancet 2001, 357, 539-545.

62. Hussain, S.P.; Harris, C.C. Inflammation and cancer: an ancient link with novel potentials. Int. J. Cancer 2007, 121, 2373-2380.

63. Moncada, S. Nitric oxide in the vasculature: physiology and pathophysiology. Ann. N Y. Acad. Sci. 1997, 811, 60-67; discussion 67-69.

64. Murata, J.; Tada, M.; Iggo, R.D.; Sawamura, Y.; Shinohe, Y.; Abe, H. Nitric oxide as a carcinogen: analysis by yeast functional assay of inactivating p53 mutations induced by nitric oxide. Mutat. Res. 1997, 379, 211-218.

65. Lala, P.K.; Chakraborty, C. Role of nitric oxide in carcinogenesis and tumour progression. Lancet Oncol. 2001, 2, 149-156.

66. Grimm, E.A.; Ellerhorst, J.; Tang, C.H.; Ekmekcioglu, S. Constitutive intracellular production of iNOS and NO in human melanoma: possible role in regulation of growth and resistance to apoptosis. Nitric Oxide 2008, 19, 133-137.

67. Kundu, J.K.; Surh, Y.J. Inflammation: gearing the journey to cancer. Mutat. Res. 2008, 659, 15-30.

68. Liu, Y.; Gao, W.; Zhang, D. Effects of cigarette smoke extract on A549 cells and human lung fibroblasts treated with transforming growth factor-beta1 in a coculture system. Clin. Exp. Med. 2009, doi: 10.1007/s10238-009-0081-x.

69. Halliday, G.M. Inflammation, gene mutation and photoimmunosuppression in response to UVRinduced oxidative damage contributes to photocarcinogenesis. Mutat. Res. 2005, 571, 107-120.

70. Rajalingam, K.; Schreck, R.; Rapp, U.R.; Albert, S. Ras oncogenes and their downstream targets. Biochim. Biophys. Acta 2007, 1773, 1177-1195.

71. Strano, S.; Dell'Orso, S.; Di Agostino, S.; Fontemaggi, G.; Sacchi, A.; Blandino, G. Mutant p53: an oncogenic transcription factor. Oncogene 2007, 26, 2212-2219.

72. Nishigori, C.; Hattori, Y.; Toyokuni, S. Role of reactive oxygen species in skin carcinogenesis. Antioxid. Redox Signal 2004, 6, 561-570.

73. Ortega, A.; Carretero, J.; Obrador, E.; Estrela, J.M. Tumoricidal activity of endothelium-derived NO and the survival of metastatic cells with high GSH and Bcl-2 levels. Nitric Oxide 2008, 19, 107-114.

74. Thiery, J.P. Epithelial-mesenchymal transitions in tumour progression. Nat. Rev. Cancer 2002, 2, 442-454.

75. Frame, M.C. Src in cancer: deregulation and consequences for cell behaviour. Biochim. Biophys. Acta 2002, 1602, 114-130. 
76. Mehdi, M.Z.; Pandey, N.R.; Pandey, S.K.; Srivastava, A.K. H2O2-induced phosphorylation of ERK1/2 and PKB requires tyrosine kinase activity of insulin receptor and c-Src. Antioxid. Redox Signal 2005, 7, 1014-1020.

77. Sato, H.; Sato, M.; Kanai, H.; Uchiyama, T.; Iso, T.; Ohyama, Y.; Sakamoto, H.; Tamura, J.; Nagai, R.; Kurabayashi, M. Mitochondrial reactive oxygen species and c-Src play a critical role in hypoxic response in vascular smooth muscle cells. Cardiovasc. Res. 2005, 67, 714-722.

78. Saito, S.; Frank, G.D.; Mifune, M.; Ohba, M.; Utsunomiya, H.; Motley, E.D.; Inagami, T.; Eguchi, S. Ligand-independent trans-activation of the platelet-derived growth factor receptor by reactive oxygen species requires protein kinase C-delta and c-Src. J. Biol. Chem. 2002, 277, 44695-44700.

79. Basuroy, S.; Sheth, P.; Kuppuswamy, D.; Balasubramanian, S.; Ray, R.M.; Rao, R.K. Expression of kinase-inactive c-Src delays oxidative stress-induced disassembly and accelerates calciummediated reassembly of tight junctions in the Caco-2 cell monolayer. J. Biol. Chem. 2003, 278, 11916-11924.

80. Thomas, S.M.; Brugge, J.S. Cellular functions regulated by Src family kinases. Annu. Rev. Cell Dev. Biol. 1997, 13, 513-609.

81. Ma, Y.C.; Huang, X.Y. Novel regulation and function of Src tyrosine kinase. Cell Mol. Life Sci. 2002, 59, 456-462.

82. Kemble, D.J.; Sun, G. Direct and specific inactivation of protein tyrosine kinases in the Src and FGFR families by reversible cysteine oxidation. Proc. Natl. Acad. Sci. USA 2009, 106, 5070-5075.

83. Oo, M.L.; Senga, T.; Thant, A.A.; Amin, A.R.; Huang, P.; Mon, N.N.; Hamaguchi, M. Cysteine residues in the $\mathrm{C}$-terminal lobe of Src: their role in the suppression of the Src kinase. Oncogene 2003, 22, 1411-1417.

84. Senga, T.; Hasegawa, H.; Tanaka, M.; Rahman, M.A.; Ito, S.; Hamaguchi, M. The cysteinecluster motif of c-Src: its role for the heavy metal-mediated activation of kinase. Cancer Sci. 2008, 99, 571-575.

85. Rahman, M.A.; Senga, T.; Oo, M.L.; Hasegawa, H.; Biswas, M.H.; Mon, N.N.; Huang, P.; Ito, S.; Yamamoto, T.; Hamaguchi, M. The cysteine-cluster motif of c-Yes, Lyn and FAK as a suppressive module for the kinases. Oncol. Rep. 2008, 19, 975-980.

86. Giannoni, E.; Buricchi, F.; Raugei, G.; Ramponi, G.; Chiarugi, P. Intracellular reactive oxygen species activate Src tyrosine kinase during cell adhesion and anchorage-dependent cell growth. Mol. Cell Biol. 2005, 25, 6391-6403.

87. Inumaru, J.; Nagano, O.; Takahashi, E.; Ishimoto, T.; Nakamura, S.; Suzuki, Y.; Niwa, S.; Umezawa, K.; Tanihara, H.; Saya, H. Molecular mechanisms regulating dissociation of cell-cell junction of epithelial cells by oxidative stress. Genes Cells 2009, 14, 703-716.

88. Akhand, A.A.; Pu, M.; Senga, T.; Kato, M.; Suzuki, H.; Miyata, T.; Hamaguchi, M.; Nakashima, I. Nitric oxide controls src kinase activity through a sulfhydryl group modification-mediated Tyr527-independent and Tyr-416-linked mechanism. J. Biol. Chem. 1999, 274, 25821-25826.

89. Rahman, M.A.; Senga, T.; Ito, S.; Hyodo, T.; Hasegawa, H.; Hamaguchi, M. S-nitrosylation at cysteine 498 of c-Src tyrosine kinase regulates nitric oxide-mediated cell invasion. J. Biol. Chem. 2009, 285, 3806-3814. 
90. Onder, T.T.; Gupta, P.B.; Mani, S.A.; Yang, J.; Lander, E.S.; Weinberg, R.A. Loss of E-cadherin promotes metastasis via multiple downstream transcriptional pathways. Cancer Res. 2008, 68, 3645-3654.

91. Fidler, I.J. The pathogenesis of cancer metastasis: the 'seed and soil' hypothesis revisited. Nat. Rev. Cancer 2003, 3, 453-458.

92. Sahai, E. Illuminating the metastatic process. Nat. Rev. Cancer 2007, 7, 737-749.

93. Chambers, A.F.; Groom, A.C.; MacDonald, I.C. Dissemination and growth of cancer cells in metastatic sites. Nat. Rev. Cancer 2002, 2, 563-572.

94. Weiss, L.; Nannmark, U.; Johansson, B.R.; Bagge, U. Lethal deformation of cancer cells in the microcirculation: a potential rate regulator of hematogenous metastasis. Int. J. Cancer 1992, 50, 103-107.

95. Al-Mehdi, A.B.; Tozawa, K.; Fisher, A.B.; Shientag, L.; Lee, A.; Muschel, R.J. Intravascular origin of metastasis from the proliferation of endothelium-attached tumor cells: a new model for metastasis. Nat. Med. 2000, 6, 100-102.

96. Radomski, M.W.; Palmer, R.M.; Moncada, S. An L-arginine/nitric oxide pathway present in human platelets regulates aggregation. Proc. Natl. Acad. Sci. USA 1990, 87, 5193-5197.

97. Radomski, M.W.; Jenkins, D.C.; Holmes, L.; Moncada, S. Human colorectal adenocarcinoma cells: differential nitric oxide synthesis determines their ability to aggregate platelets. Cancer Res. 1991, 51, 6073-6078.

98. Rao, R.M.; Yang, L.; Garcia-Cardena, G.; Luscinskas, F.W. Endothelial-dependent mechanisms of leukocyte recruitment to the vascular wall. Circ. Res. 2007, 101, 234-247.

99. Ben-Baruch, A. Organ selectivity in metastasis: regulation by chemokines and their receptors. Clin. Exp. Metastasis 2008, 25, 345-356.

100. Gassmann, P.; Haier, J. The tumor cell-host organ interface in the early onset of metastatic organ colonisation. Clin. Exp. Metastasis 2008, 25, 171-181.

101. Koukoulis, G.K.; Patriarca, C.; Gould, V.E. Adhesion molecules and tumor metastasis. Hum. Pathol. 1998, 29, 889-892.

102. Borsig, L.; Wong, R.; Hynes, R.O.; Varki, N.M.; Varki, A. Synergistic effects of L- and Pselectin in facilitating tumor metastasis can involve non-mucin ligands and implicate leukocytes as enhancers of metastasis. Proc. Natl. Acad. Sci. USA 2002, 99, 2193-2198.

103. Mehlen, P.; Puisieux, A. Metastasis: a question of life or death. Nat. Rev. Cancer 2006, 6, 449-458.

104. Orr, F.W.; Wang, H.H.; Lafrenie, R.M.; Scherbarth, S.; Nance, D.M. Interactions between cancer cells and the endothelium in metastasis. J. Pathol. 2000, 190, 310-329.

105. Estrela, J.M.; Ortega, A.; Obrador, E. Glutathione in cancer biology and therapy. Crit. Rev. Clin. Lab. Sci. 2006, 43, 143-181.

106. Fidler, I.J.; Nicolson, G.L. Organ selectivity for implantation survival and growth of B16 melanoma variant tumor lines. J. Natl. Cancer Inst. 1976, 57, 1199-1202.

107. Garofalo, A.; Chirivi, R.G.; Foglieni, C.; Pigott, R.; Mortarini, R.; Martin-Padura, I.; Anichini, A.; Gearing, A.J.; Sanchez-Madrid, F.; Dejana, E.; et al. Involvement of the very late antigen 4 integrin on melanoma in interleukin 1-augmented experimental metastases. Cancer Res. 1995, 55, 414-419. 
108. Klemke, M.; Weschenfelder, T.; Konstandin, M.H.; Samstag, Y. High affinity interaction of integrin alpha4beta1 (VLA-4) and vascular cell adhesion molecule 1 (VCAM-1) enhances migration of human melanoma cells across activated endothelial cell layers. J. Cell Physiol. 2007, $212,368-374$.

109. Marui, N.; Offermann, M.K.; Swerlick, R.; Kunsch, C.; Rosen, C.A.; Ahmad, M.; Alexander, R.W.; Medford, R.M. Vascular cell adhesion molecule-1 (VCAM-1) gene transcription and expression are regulated through an antioxidant-sensitive mechanism in human vascular endothelial cells. J. Clin. Invest. 1993, 92, 1866-1874.

110. Bayon, L.G.; Izquierdo, M.A.; Sirovich, I.; van Rooijen, N.; Beelen, R.H.; Meijer, S. Role of Kupffer cells in arresting circulating tumor cells and controlling metastatic growth in the liver. Hepatology 1996, 23, 1224-1231.

111. Anasagasti, M.J.; Olaso, E.; Calvo, F.; Mendoza, L.; Martin, J.J.; Bidaurrazaga, J.; VidalVanaclocha, F. Interleukin 1-dependent and -independent mouse melanoma metastases. J. Natl. Cancer Inst. 1997, 89, 645-651.

112. Mendoza, L.; Olaso, E.; Anasagasti, M.J.; Fuentes, A.M.; Vidal-Vanaclocha, F. Mannose receptor-mediated endothelial cell activation contributes to B16 melanoma cell adhesion and metastasis in liver. J. Cell Physiol. 1998, 174, 322-330.

113. Burdon, R.H. Superoxide and hydrogen peroxide in relation to mammalian cell proliferation. Free Radic. Biol. Med. 1995, 18, 775-794.

114. Blanchetot, C.; Boonstra, J. The ROS-NOX connection in cancer and angiogenesis. Crit. Rev. Eukaryot. Gene Expr. 2008, 18, 35-45.

115. Hancock, J.T. The role of redox mechanisms in cell signalling. Mol. Biotechnol. 2009, 43, 162-166.

116. Nishikawa, M. Reactive oxygen species in tumor metastasis. Cancer Lett. 2008, 266, 53-59.

117. Ishikawa, K.; Koshikawa, N.; Takenaga, K.; Nakada, K.; Hayashi, J. Reversible regulation of metastasis by ROS-generating mtDNA mutations. Mitochondrion 2008, 8, 339-344.

118. Lorusso, G.; Ruegg, C. The tumor microenvironment and its contribution to tumor evolution toward metastasis. Histochem. Cell Biol. 2008, 130, 1091-1103.

119. Fukumura, D.; Kashiwagi, S.; Jain, R.K. The role of nitric oxide in tumour progression. Nat. Rev. Cancer 2006, 6, 521-534.

120. Sonveaux, P.; Jordan, B.F.; Gallez, B.; Feron, O. Nitric oxide delivery to cancer: why and how? Eur. J. Cancer. 2009, 45, 1352-1369.

121. Jadeski, L.C.; Chakraborty, C.; Lala, P.K. Nitric oxide-mediated promotion of mammary tumour cell migration requires sequential activation of nitric oxide synthase, guanylate cyclase and mitogen-activated protein kinase. Int. J. Cancer 2003, 106, 496-504.

122. Wang, L.; Shi, G.G.; Yao, J.C.; Gong, W.; Wei, D.; Wu, T.T.; Ajani, J.A.; Huang, S.; Xie, K. Expression of endothelial nitric oxide synthase correlates with the angiogenic phenotype of and predicts poor prognosis in human gastric cancer. Gastric Cancer 2005, 8, 18-28.

123. Tu, Y.T.; Tao, J.; Liu, Y.Q.; Li, Y.; Huang, C.Z.; Zhang, X.B.; Lin, Y. Expression of endothelial nitric oxide synthase and vascular endothelial growth factor in human malignant melanoma and their relation to angiogenesis. Clin. Exp. Dermatol. 2006, 31, 413-418. 
124. Williams, E.L.; Djamgoz, M.B. Nitric oxide and metastatic cell behaviour. Bioessays 2005, 27, 1228-1238.

125. Ferreira, H.H.; Costa, R.A.; Jacheta, J.M.; Martins, A.R.; Medeiros, M.V.; Macedo-Soares, M.F.; De Luca, I.M.; Antunes, E.; De Nucci, G. Modulation of eosinophil migration from bone marrow to lungs of allergic rats by nitric oxide. Biochem. Pharmacol. 2004, 68, 631-639.

126. Clancy, R.; Leszczynska, J.; Amin, A.; Levartovsky, D.; Abramson, S.B. Nitric oxide stimulates ADP ribosylation of actin in association with the inhibition of actin polymerization in human neutrophils. J. Leukoc. Biol. 1995, 58, 196-202.

127. Dal Secco, D.; Paron, J.A.; de Oliveira, S.H.; Ferreira, S.H.; Silva, J.S.; Cunha Fde, Q. Neutrophil migration in inflammation: nitric oxide inhibits rolling, adhesion and induces apoptosis. Nitric Oxide 2003, 9, 153-164.

128. Ozturk, H.; Buyukbayram, H.; Ozdemir, E.; Ketani, A.; Gurel, A.; Onen, A.; Otcu, S. The effects of nitric oxide on the expression of cell adhesion molecules (ICAM-1, UEA-1, and tenascin) in rats with unilateral testicular torsion. J. Pediatr. Surg. 2003, 38, 1621-1627.

129. Radisavljevic, Z.; Avraham, H.; Avraham, S. Vascular endothelial growth factor up-regulates ICAM-1 expression via the phosphatidylinositol $3 \mathrm{OH}$-kinase/AKT/Nitric oxide pathway and modulates migration of brain microvascular endothelial cells. J. Biol. Chem. 2000, 275, 20770-20774.

130. Wang, H.H.; McIntosh, A.R.; Hasinoff, B.B.; Rector, E.S.; Ahmed, N.; Nance, D.M.; Orr, F.W. B16 melanoma cell arrest in the mouse liver induces nitric oxide release and sinusoidal cytotoxicity: a natural hepatic defense against metastasis. Cancer Res. 2000, 60, 5862-5869.

131. Hirst, D.G.; Robson, T. Nitrosative stress in cancer therapy. Front Biosci. 2007, 12, 3406-3418.

132. Lechner, M.; Lirk, P.; Rieder, J. Inducible nitric oxide synthase (iNOS) in tumor biology: the two sides of the same coin. Semin. Cancer Biol. 2005, 15, 277-289.

133. Carretero, J.; Obrador, E.; Esteve, J.M.; Ortega, A.; Pellicer, J.A.; Sempere, F.V.; Estrela, J.M. Tumoricidal activity of endothelial cells. Inhibition of endothelial nitric oxide production abrogates tumor cytotoxicity induced by hepatic sinusoidal endothelium in response to B16 melanoma adhesion in vitro. J. Biol. Chem. 2001, 276, 25775-25782.

134. Qiu, H.; Orr, F.W.; Jensen, D.; Wang, H.H.; McIntosh, A.R.; Hasinoff, B.B.; Nance, D.M.; Pylypas, S.; Qi, K.; Song, C.; Muschel, R.J.; Al-Mehdi, A.B. Arrest of B16 melanoma cells in the mouse pulmonary microcirculation induces endothelial nitric oxide synthase-dependent nitric oxide release that is cytotoxic to the tumor cells. Am. J. Pathol. 2003, 162, 403-412.

135. Jessup, J.M.; Battle, P.; Waller, H.; Edmiston, K.H.; Stolz, D.B.; Watkins, S.C.; Locker, J.; Skena, K. Reactive nitrogen and oxygen radicals formed during hepatic ischemia-reperfusion kill weakly metastatic colorectal cancer cells. Cancer Res. 1999, 59, 1825-1829.

136. Vidal-Vanaclocha, F. The prometastatic microenvironment of the liver. Cancer Microenviron. 2008, 1, 113-129.

137. Albertsson, P.A.; Nannmark, U.; Johansson, B.R. Melanoma cell destruction in the microvasculature of perfused hearts is reduced by pretreatment with vitamin E. Clin. Exp. Metastasis 1995, 13, 269-276. 
138. Eskenazi, A.E.; Pinkas, J.; Whitin, J.C.; Arguello, F.; Cohen, H.J.; Frantz, C.N. Role of antioxidant enzymes in the induction of increased experimental metastasis by hydroxyurea. $J$. Natl. Cancer Inst. 1993, 85, 711-721.

139. Anasagasti, M.J.; Martin, J.J.; Mendoza, L.; Obrador, E.; Estrela, J.M.; McCuskey, R.S.; VidalVanaclocha, F. Glutathione protects metastatic melanoma cells against oxidative stress in the murine hepatic microvasculature. Hepatology 1998, 27, 1249-1256.

140. Carretero, J.; Obrador, E.; Anasagasti, M.J.; Martin, J.J.; Vidal-Vanaclocha, F.; Estrela, J.M. Growth-associated changes in glutathione content correlate with liver metastatic activity of B16 melanoma cells. Clin. Exp. Metastasis 1999, 17, 567-574.

141. Obrador, E.; Carretero, J.; Ortega, A.; Medina, I.; Rodilla, V.; Pellicer, J.A.; Estrela, J.M. gamma-Glutamyl transpeptidase overexpression increases metastatic growth of B16 melanoma cells in the mouse liver. Hepatology 2002, 35, 74-81.

142. Ortega, A.L.; Carretero, J.; Obrador, E.; Gambini, J.; Asensi, M.; Rodilla, V.; Estrela, J.M. Tumor cytotoxicity by endothelial cells. Impairment of the mitochondrial system for glutathione uptake in mouse B16 melanoma cells that survive after in vitro interaction with the hepatic sinusoidal endothelium. J. Biol. Chem. 2003, 278, 13888-13897.

143. Meister, A. Glutathione deficiency produced by inhibition of its synthesis, and its reversal; applications in research and therapy. Pharmacol. Ther. 1991, 51, 155-194.

144. Kroemer, G.; Galluzzi, L.; Brenner, C. Mitochondrial membrane permeabilization in cell death. Physiol. Rev. 2007, 87, 99-163.

145. Vahrmeijer, A.L.; Hoetelmans, R.W.; Mulder, G.J.; Schutrups, J.; van Vlierberghe, R.L.; van de Velde, C.J.; van Dierendonck, J.H. Development of resistance to glutathione depletion-induced cell death in CC531 colon carcinoma cells: association with increased expression of bcl-2. Biochem. Pharmacol. 2000, 59, 1557-1562.

146. Baliga, B.C.; Kumar, S. Role of Bcl-2 family of proteins in malignancy. Hematol. Oncol. 2002, 20, 63-74.

147. Takaoka, A.; Adachi, M.; Okuda, H.; Sato, S.; Yawata, A.; Hinoda, Y.; Takayama, S.; Reed, J.C.; Imai, K. Anti-cell death activity promotes pulmonary metastasis of melanoma cells. Oncogene 1997, 14, 2971-2977.

148. Owen-Schaub, L.B.; van Golen, K.L.; Hill, L.L.; Price, J.E. Fas and Fas ligand interactions suppress melanoma lung metastasis. J. Exp. Med. 1998, 188, 1717-1723.

149. Lowe, S.W.; Lin, A.W. Apoptosis in cancer. Carcinogenesis 2000, 21, 485-495.

150. Wong, C.W.; Lee, A.; Shientag, L.; Yu, J.; Dong, Y.; Kao, G.; Al-Mehdi, A.B.; Bernhard, E.J.; Muschel, R.J. Apoptosis: an early event in metastatic inefficiency. Cancer Res. 2001, 61, 333-338.

151. Sartorius, U.A.; Krammer, P.H. Upregulation of Bcl-2 is involved in the mediation of chemotherapy resistance in human small cell lung cancer cell lines. Int. J. Cancer 2002, 97, 584-592.

152. Hickman, J.A. Apoptosis and tumourigenesis. Curr. Opin. Genet. Dev. 2002, 12, 67-72.

153. Zimmermann, K.C.; Bonzon, C.; Green, D.R. The machinery of programmed cell death. Pharmacol. Ther. 2001, 92, 57-70. 
154. Patel, M.P.; Masood, A.; Patel, P.S.; Chanan-Khan, A.A. Targeting the Bcl-2. Curr. Opin. Oncol. 2009, 21, 516-523.

155. Ogretmen, B.; Safa, A.R. Down-regulation of apoptosis-related bcl-2 but not bcl-xL or bax proteins in multidrug-resistant MCF-7/Adr human breast cancer cells. Int. J. Cancer 1996, 67, 608-614.

156. Igney, F.H.; Krammer, P.H. Death and anti-death: tumour resistance to apoptosis. Nat. Rev. Cancer 2002, 2, 277-288.

157. Petrovic, A.S.; Young, R.L.; Hilgarth, B.; Ambros, P.; Korsmeyer, S.J.; Jaeger, U. The Ig heavy chain 3 ' end confers a posttranscriptional processing advantage to Bcl-2-IgH fusion RNA in $\mathrm{t}(14 ; 18)$ lymphoma. Blood 1998, 91, 3952-3961.

158. Schiavone, N.; Rosini, P.; Quattrone, A.; Donnini, M.; Lapucci, A.; Citti, L.; Bevilacqua, A.; Nicolin, A.; Capaccioli, S. A conserved AU-rich element in the 3' untranslated region of bcl-2 mRNA is endowed with a destabilizing function that is involved in bcl-2 down-regulation during apoptosis. Faseb J. 2000, 14, 174-184.

159. Benlloch, M.; Ortega, A.; Ferrer, P.; Segarra, R.; Obrador, E.; Asensi, M.; Carretero, J.; Estrela, J.M. Acceleration of glutathione efflux and inhibition of gamma-glutamyltranspeptidase sensitize metastatic B16 melanoma cells to endothelium-induced cytotoxicity. J. Biol. Chem. 2005, 280, 6950-6959.

160. Yasuda, H. Solid tumor physiology and hypoxia-induced chemo/radio-resistance: novel strategy for cancer therapy: nitric oxide donor as a therapeutic enhancer. Nitric Oxide 2008, 19, 205-216.

161. Dadras, S.S.; Lange-Asschenfeldt, B.; Velasco, P.; Nguyen, L.; Vora, A.; Muzikansky, A.; Jahnke, K.; Hauschild, A.; Hirakawa, S.; Mihm, M.C.; Detmar, M. Tumor lymphangiogenesis predicts melanoma metastasis to sentinel lymph nodes. Mod. Pathol. 2005, 18, 1232-1242.

162. Ono, M. Molecular links between tumor angiogenesis and inflammation: inflammatory stimuli of macrophages and cancer cells as targets for therapeutic strategy. Cancer. Sci. 2008, 99, 1501-1506.

163. Gupta, K.; Zhang, J. Angiogenesis: a curse or cure? Postgrad. Med. J. 2005, 81, 236-242.

164. Holmgren, L.; O'Reilly, M.S.; Folkman, J. Dormancy of micrometastases: balanced proliferation and apoptosis in the presence of angiogenesis suppression. Nat. Med. 1995, 1, 149-153.

165. Bertolini, F. Chemotherapy and the tumor microenvironment: the contribution of circulating endothelial cells. Cancer Metastasis Rev. 2008, 27, 95-101.

166. Watari, K.; Nakao, S.; Fotovati, A.; Basaki, Y.; Hosoi, F.; Bereczky, B.; Higuchi, R.; Miyamoto, T.; Kuwano, M.; Ono, M. Role of macrophages in inflammatory lymphangiogenesis: Enhanced production of vascular endothelial growth factor C and D through NF-kappaB activation. Biochem. Biophys. Res. Commun 2008, 377, 826-831.

167. Fang, J.; Seki, T.; Maeda, H. Therapeutic strategies by modulating oxygen stress in cancer and inflammation. Adv. Drug Deliv. Rev. 2009, 61, 290-302.

168. Moreno-Sanchez, R.; Rodriguez-Enriquez, S.; Marin-Hernandez, A.; Saavedra, E. Energy metabolism in tumor cells. Febs J. 2007, 274, 1393-1418.

169. Jackson, J.R.; Seed, M.P.; Kircher, C.H.; Willoughby, D.A.; Winkler, J.D. The codependence of angiogenesis and chronic inflammation. Faseb J. 1997, 11, 457-465. 
170. Taranova, A.G.; Maldonado, D. 3rd; Vachon, C.M.; Jacobsen, E.A.; Abdala-Valencia, H.; McGarry, M.P.; Ochkur, S.I.; Protheroe, C.A.; Doyle, A.; Grant, C.S.; Cook-Mills, J.; Birnbaumer, L.; Lee, N.A.; Lee, J.J. Allergic pulmonary inflammation promotes the recruitment of circulating tumor cells to the lung. Cancer Res. 2008, 68, 8582-8589.

171. Rice, G.E.; Gimbrone, M.A. Jr.; Bevilacqua, M.P. Tumor cell-endothelial interactions. Increased adhesion of human melanoma cells to activated vascular endothelium. Am. J. Pathol. 1988, 133, 204-210.

172. Federico, A.; Morgillo, F.; Tuccillo, C.; Ciardiello, F.; Loguercio, C. Chronic inflammation and oxidative stress in human carcinogenesis. Int. J. Cancer 2007, 121, 2381-2386.

173. Campisi, J. Senescent cells, tumor suppression, and organismal aging: good citizens, bad neighbors. Cell 2005, 120, 513-522.

174. Fidler, I.J. Metastasis: guantitative analysis of distribution and fate of tumor embolilabeled with 125 I-5-iodo-2'-deoxyuridine. J. Natl. Cancer Inst. 1970, 45, 773-782.

175. Barbera-Guillem, E.; Smith, I.; Weiss, L. Cancer-cell traffic in the liver. II. Arrest, transit and death of B16F10 and M5076 cells in the sinusoids. Int. J. Cancer 1993, 53, 298-301.

176. Weiss, L. Biomechanical interactions of cancer cells with the microvasculature during hematogenous metastasis. Cancer Metastasis Rev. 1992, 11, 227-235.

177. Bouwens, L.; Jacobs, R.; Remels, L.; Wisse, E. Natural cytotoxicity of rat hepatic natural killer cells and macrophages against a syngeneic colon adenocarcinoma. Cancer Immunol. Immunother. 1988, 27, 137-141.

178. Bockhorn, M.; Jain, R.K.; Munn, L.L. Active versus passive mechanisms in metastasis: do cancer cells crawl into vessels, or are they pushed? Lancet Oncol. 2007, 8, 444-448.

179. Weiss, L. Metastatic inefficiency. Adv. Cancer Res. 1990, 54, 159-211.

180. Trumpp, A.; Wiestler, O.D. Mechanisms of Disease: cancer stem cells--targeting the evil twin. Nat. Clin. Pract. Oncol. 2008, 5, 337-347.

181. Xie, K.; Huang, S. Regulation of cancer metastasis by stress pathways. Clin. Exp. Metastasis 2003, 20, 31-43.

182. Fratelli, M.; Goodwin, L.O.; Orom, U.A.; Lombardi, S.; Tonelli, R.; Mengozzi, M.; Ghezzi, P. Gene expression profiling reveals a signaling role of glutathione in redox regulation. Proc. Natl. Acad. Sci. USA 2005, 102, 13998-14003.

183. Zhou, Q.; Liu, L.Z.; Fu, B.; Hu, X.; Shi, X.; Fang, J.; Jiang, B.H. Reactive oxygen species regulate insulin-induced VEGF and HIF-1alpha expression through the activation of p70S6K1 in human prostate cancer cells. Carcinogenesis 2007, 28, 28-37.

184. Wu, W.S. The signaling mechanism of ROS in tumor progression. Cancer Metastasis Rev. 2006, 25, 695-705.

185. Kroncke, K.D. Mechanisms and biological consequences of nitrosative stress. Biol. Chem. 2003, 384, 1341.

186. Mena, S.; Benlloch, M.; Ortega, A.; Carretero, J.; Obrador, E.; Asensi, M.; Petschen, I.; Brown, B.D.; Estrela, J.M. Bcl-2 and glutathione depletion sensitizes B16 melanoma to combination therapy and eliminates metastatic disease. Clin. Cancer Res. 2007, 13, 2658-2666. 
187. Ferrer, P.; Asensi, M.; Priego, S.; Benlloch, M.; Mena, S.; Ortega, A.; Obrador, E.; Esteve, J.M.; Estrela, J.M. Nitric oxide mediates natural polyphenol-induced Bcl-2 down-regulation and activation of cell death in metastatic B16 melanoma. J. Biol. Chem. 2007, 282, 2880-2890.

188. Chanvorachote, P.; Nimmannit, U.; Stehlik, C.; Wang, L.; Jiang, B.H.; Ongpipatanakul, B.; Rojanasakul, Y. Nitric oxide regulates cell sensitivity to cisplatin-induced apoptosis through Snitrosylation and inhibition of Bcl-2 ubiquitination. Cancer Res. 2006, 66, 6353-6360.

189. Azad, N.; Vallyathan, V.; Wang, L.; Tantishaiyakul, V.; Stehlik, C.; Leonard, S.S.; Rojanasakul, Y. S-nitrosylation of Bcl-2 inhibits its ubiquitin-proteasomal degradation. A novel antiapoptotic mechanism that suppresses apoptosis. J. Biol. Chem. 2006, 281, 34124-34134.

190. Wang, J.; Yi, J. Cancer cell killing via ROS: to increase or decrease, that is the question. Cancer Biol. Ther. 2008, 7, 1875-1884.

191. Ramsey, M.R.; Sharpless, N.E. ROS as a tumour suppressor? Nat. Cell Biol. 2006, 8, 1213-1215.

192. D'Autreaux, B.; Toledano, M.B. ROS as signalling molecules: mechanisms that generate specificity in ROS homeostasis. Nat. Rev. Mol. Cell Biol. 2007, 8, 813-824.

193. Ushio-Fukai, M.; Nakamura, Y. Reactive oxygen species and angiogenesis: NADPH oxidase as target for cancer therapy. Cancer Lett. 2008, 266, 37-52.

194. Clerkin, J.S.; Naughton, R.; Quiney, C.; Cotter, T.G. Mechanisms of ROS modulated cell survival during carcinogenesis. Cancer Lett. 2008, 266, 30-36.

195. Wu, X.J.; Hua, X. Targeting ROS: selective killing of cancer cells by a cruciferous vegetable derived pro-oxidant compound. Cancer Biol. Ther. 2007, 6, 646-647.

196. Giles, G.I. The redox regulation of thiol dependent signaling pathways in cancer. Curr. Pharm. Des. 2006, 12, 4427-4443.

197. Koeberle, A.; Northoff, H.; Werz, O. Curcumin blocks prostaglandin E2 biosynthesis through direct inhibition of the microsomal prostaglandin E2 synthase-1. Mol. Cancer Ther. 2009, 8, 2348-2355.

198. Purkayastha, S.; Berliner, A.; Fernando, S.S.; Ranasinghe, B.; Ray, I.; Tariq, H.; Banerjee, P. Curcumin blocks brain tumor formation. Brain Res. 2009, 1266, 130-138.

199. Malhotra, A.; Nair, P.; Dhawan, D.K. Modulatory effects of curcumin and resveratrol on lung carcinogenesis in mice. Phytother. Res. 2009, DOI: 10.1002/ptr.3087.

200. Bishayee, A.; Politis, T.; Darvesh, A.S. Resveratrol in the chemoprevention and treatment of hepatocellular carcinoma. Cancer Treat. Rev. 2009, 36, 43-45.

201. Sengottuvelan, M.; Deeptha, K.; Nalini, N. Resveratrol ameliorates DNA damage, prooxidant and antioxidant imbalance in 1,2-dimethylhydrazine induced rat colon carcinogenesis. Chem. Biol. Interact. 2009, 181, 193-201.

202. Yang, Z.; Yang, S.; Misner, B.J.; Chiu, R.; Liu, F.; Meyskens, F.L. Jr. Nitric oxide initiates progression of human melanoma via a feedback loop mediated by apurinic/apyrimidinic endonuclease-1/redox factor-1, which is inhibited by resveratrol. Mol. Cancer Ther. 2008, 7, 3751-3760.

203. Paul, S.; Decastro, A.; Lee, H.J.; Smolarek, A.K.; So, J.Y.; Simi, B.; Wang, C.X.; Zhou, R.; Rimando, A.M.; Suh, N. Dietary intake of pterostilbene, a constituent of blueberries, inhibits the \{beta\}-catenin/p65 downstream signaling pathway and colon carcinogenesis in rats. Carcinogenesis 2010, in press. 
204. Cichocki, M.; Paluszczak, J.; Szaefer, H.; Piechowiak, A.; Rimando, A.M.; Baer-Dubowska, W. Pterostilbene is equally potent as resveratrol in inhibiting 12-O-tetradecanoylphorbol-13-acetate activated NFkappaB, AP-1, COX-2, and iNOS in mouse epidermis. Mol. Nutr. Food Res. 2008, 52 (Suppl. 1), S62-S70.

205. Fu, H.; He, J.; Mei, F.; Zhang, Q.; Hara, Y.; Ryota, S.; Lubet, R.A.; Chen, R.; Chen, D.R.; You, M. Lung cancer inhibitory effect of epigallocatechin-3-gallate is dependent on its presence in a complex mixture (polyphenon E). Cancer Prev. Res. (Phila Pa) 2009, 2, 531-537.

206. Butt, M.S.; Sultan, M.T. Green tea: nature's defense against malignancies. Crit. Rev. Food Sci. Nutr. 2009, 49, 463-473.

207. Shan, B.E.; Wang, M.X.; Li, R.Q. Quercetin inhibit human SW480 colon cancer growth in association with inhibition of cyclin D1 and survivin expression through Wnt/beta-catenin signaling pathway. Cancer Invest. 2009, 27, 604-612.

208. Murakami, A.; Ashida, H.; Terao, J. Multitargeted cancer prevention by quercetin. Cancer Lett. 2008, 269, 315-325.

209. Ng, Q.S.; Goh, V.; Milner, J.; Stratford, M.R.; Folkes, L.K.; Tozer, G.M.; Saunders, M.I.; Hoskin, P.J. Effect of nitric-oxide synthesis on tumour blood volume and vascular activity: a phase I study. Lancet Oncol. 2007, 8, 111-118.

210. Ozben, T. Oxidative stress and apoptosis: impact on cancer therapy. J. Pharm. Sci. 2007, 96, 2181-2196.

211. Renschler, M.F. The emerging role of reactive oxygen species in cancer therapy. Eur. J. Cancer 2004, 40, 1934-1940.

212. Brune, B.; Zhou, J. Nitric oxide and superoxide: interference with hypoxic signaling. Cardiovasc. Res. 2007, 75, 275-282.

213. Priego, S.; Feddi, F.; Ferrer, P.; Mena, S.; Benlloch, M.; Ortega, A.; Carretero, J.; Obrador, E.; Asensi, M.; Estrela, J.M. Natural polyphenols facilitate elimination of HT-29 colorectal cancer xenografts by chemoradiotherapy: a Bcl-2- and superoxide dismutase 2-dependent mechanism. Mol. Cancer Ther. 2008, 7, 3330-3342.

214. Roy, P.; Nigam, N.; George, J.; Srivastava, S.; Shukla, Y. Induction of apoptosis by tea polyphenols mediated through mitochondrial cell death pathway in mouse skin tumors. Cancer Biol. Ther. 2009, 8, 1281-1287.

215. Halder, B.; Bhattacharya, U.; Mukhopadhyay, S.; Giri, A.K. Molecular mechanism of black tea polyphenols induced apoptosis in human skin cancer cells: involvement of Bax translocation and mitochondria mediated death cascade. Carcinogenesis 2008, 29, 129-138.

216. Schneider, J.G.; Alosi, J.A.; McDonald, D.E.; McFadden, D.W. Pterostilbene Inhibits Lung Cancer Through Induction of Apoptosis. J. Surg. Res. 2009, doi:10.1016/j.jss.2009.06.027.

217. Alosi, J.A.; McDonald, D.E.; Schneider, J.S.; Privette, A.R.; McFadden, D.W. Pterostilbene Inhibits Breast Cancer In Vitro Through Mitochondrial Depolarization and Induction of CaspaseDependent Apoptosis. J. Surg. Res. 2009, doi:10.1016/j.jss.2009.07.027.

218. Yu, Y.; Kanwar, S.S.; Patel, B.B.; Nautiyal, J.; Sarkar, F.H.; Majumdar, A.P. Elimination of Colon Cancer Stem-Like Cells by the Combination of Curcumin and FOLFOX. Transl. Oncol. 2009, 2, 321-328. 
219. Yoon, M.J.; Kim, E.H.; Lim, J.H.; Kwon, T.K.; Choi, K.S. Superoxide anion and proteasomal dysfunction contribute to curcumin-induced paraptosis of malignant breast cancer cells. Free Radic. Biol. Med. 2009, 48, 713-726.

(C) 2010 by the authors; licensee Molecular Diversity Preservation International, Basel, Switzerland. This article is an open-access article distributed under the terms and conditions of the Creative Commons Attribution license (http://creativecommons.org/licenses/by/3.0/). 